This is the author's final, peer-reviewed manuscript as accepted for publication. The publisher-formatted version may be available through the publisher's web site or your institution's library.

\title{
Human $\beta 2$-glycoprotein I attenuates mouse intestinal ischemia/reperfusion induced injury and inflammation
}

Maurizio Tomasi, Yasuaki Hiromasa, Michael R. Pope, Sushanth Gudlur, John M.

Tomich, and Sherry D. Fleming

\section{How to cite this manuscript}

If you make reference to this version of the manuscript, use the following information:

Tomasi, M., Hiromasa, Y., Pope, M. R., Gudlur, S., Tomich, J. M., \& Fleming, S. D. (2012). Human $\beta 2$-glycoprotein I attenuates mouse intestinal ischemia/reperfusion induced injury and inflammation. Retrieved from http://krex.ksu.edu

\section{Published Version Information}

Citation: Tomasi, M., Hiromasa, Y., Pope, M. R., Gudlur, S., Tomich, J. M., \& Fleming, S. D. (2012). Human $\beta 2$-glycoprotein I attenuates mouse intestinal ischemia/reperfusion induced injury and inflammation. Molecular Immunology, 52(3-4), 207-216.

Copyright: @ 2012 Elsevier Ltd.

Digital Object Identifier (DOI): doi:10.1016/j.molimm.2012.05.018

Publisher's Link: http://www.sciencedirect.com/science/article/pii/S0161589012003197

This item was retrieved from the K-State Research Exchange (K-REx), the institutional repository of Kansas State University. K-REx is available at http://krex.ksu.edu 
Human $\beta 2$-glycoprotein I attenuates mouse intestinal ischemia/reperfusion induced injury and inflammation

Maurizio Tomasi ${ }^{1}$, Yasuaki Hiromasa ${ }^{2}$, Michael R. Pope ${ }^{1}$, Sushanth Gudlur ${ }^{2}$, John M. Tomich ${ }^{2}$ and Sherry D Fleming ${ }^{1}$

${ }^{1}$ Division of Biology, ${ }^{2}$ Department of Biochemistry, Kansas State University, Manhattan, KS

66506

Running title: Human $\beta 2-\mathrm{GPI}$ attenuates mouse IR injury

Key words: apolipoprotein $\mathrm{H}$; prostaglandin E2; mouse; ischemia

Address for correspondence:

Sherry D. Fleming, Ph.D.

18 Ackert Hall

Kansas State University

Manhattan, KS 66506

785-532-6130 (voice)

785-532-6653 (fax)

sdflemin@ksu.edu 


\begin{abstract}
Intestinal ischemia-reperfusion (IR)-induced injury results from a complex cascade of inflammatory components. In the mouse model of intestinal IR, the serum protein, $\beta 2$ glycoprotein I ( $\beta 2-\mathrm{GPI})$ binds to the cell surface early in the cascade. The bound $\beta 2-\mathrm{GPI}$ undergoes a conformational change which exposes a neoantigen recognized by naturally occurring antibodies and initiates the complement cascade. We hypothesized that providing additional antigen with exogenous $\beta 2$-GPI would alter IR-induced tissue injury. Administration of human but not mouse $\beta 2-$ GPI attenuated IR-induced tissue damage and prostaglandin $E_{2}$ production indicating a physiological difference between $\beta 2-$ GPI isolated from the two species. To investigate whether structural features were responsible for this physiological difference, we compared the chemical, physical and biochemical properties of the two proteins. Despite possessing $76 \%$ amino acid identity and $86 \%$ sequence homology, we found that mouse $\beta 2$ GPI differs from the human protein in size, carbohydrate chain location, heterogeneity and secondary structural content. These data suggest that the structural differences result in mouse Ab recognition of soluble human but not mouse $\beta 2$-GPI and attenuated IR-induced injury. We conclude that caution should be exercised in interpreting results obtained by using human $\beta 2$ GPI in a mouse model.
\end{abstract}




\section{Introduction}

Ischemia induces tissue damage which is exacerbated during subsequent tissue reperfusion. Multiple studies identified a sequence of events that lead to increased injury and inflammation. The sequence requires formation of a cell bound antigen/antibody complex resulting in excessive complement activation and prostaglandin $\mathrm{E}_{2}\left(\mathrm{PGE}_{2}\right)$ production (Austen et al., 1999; Fruchterman et al., 1998; Hill et al., 1992; Moses et al., 2009). Previous studies indicated that complement activation is required for intestinal injury with all three complement initiating pathways playing a role (Chen et al., 2009; Hart et al., 2005; Williams et al., 1999). Other studies indicated that $\mathrm{PGE}_{2}$ production is necessary but not sufficient for ischemia/reperfusion (IR)-induced intestinal damage (Moses et al., 2009; Pope et al., 2010). The requirement for naturally occurring antibodies $(\mathrm{Ab})$ in IR-induced, complement-mediated tissue injury and PGE 2

production was previously established ( Weiser et al., 1996; Williams et al., 1999; Sparkes et al., 2010). Together these studies present a complex pathogenic cascade of inflammatory components triggering IR-induced tissue damage.

In contrast to the mechanisms of injury, the specific antigens recognized by the Ab are not as clearly defined. Naturally occurring Ab frequently bind with low affinity and cross react with multiple antigens (Avrameas, 1991; Martin and Kearney, 2000). Multiple antigen/antibody complexes have been identified as initiators of IR-induced injury, including non-muscle myosin and annexin IV (Kulik et al., 2009; Zhang et al., 2004). Previously, we demonstrated that naturally occurring anti- $\beta 2$ glycoprotein I ( $\beta 2-\mathrm{GPI}) \mathrm{Ab}$ are instrumental in intestinal IR-induced tissue damage (Fleming et al., 2004). In addition, peptides derived from the mouse $\beta 2-\mathrm{GPI}$ sequence attenuated $\beta 2-$ GPI binding to cell membranes and subsequent intestinal injury in the mouse model of intestinal IR (Fleming et al., 2010). Together, these data suggest that natural Ab recognition of cell surface bound $\beta 2-\mathrm{GPI}$ is critical to IR-induced tissue damage. 
B2-GPI, also referred to as apolipoprotein $\mathrm{H}$, is a heavily glycosylated, $43 \mathrm{kDa}$ protein found in the plasma (Gries et al., 1989). Purified human $\beta 2-G P I$ contains multiple glycosylation sites with varied sialic acid content yielding 5-7 species with different isoelectric points (Gries et al., 1989). The 3D structure of membrane-bound human $\beta 2$-GPI indicates five domains in a J-shaped chain (open conformation) whereas the soluble protein appears to be a condensed ring-like structure (closed conformation) (Agar et al., 2010; Hammel et al., 2002; Schwarzenbacher et al., 1999). Importantly, Ab recognition of the protein requires neoantigen exposure that occurs when B2-GPI binds to a cell surface and takes on the J-shaped chain conformation (Fig. 1A). Domain 5 contains three disulfide bonds, a lysine rich peptide sequence and a hydrophobic quadruplet (Bouma et al., 1999) which interact and bind with amphipathic anionic molecules such as phosphatidylserine exposed on early apoptotic cells (Balasubramanian et al., 1997; Balasubramanian et al., 2005).

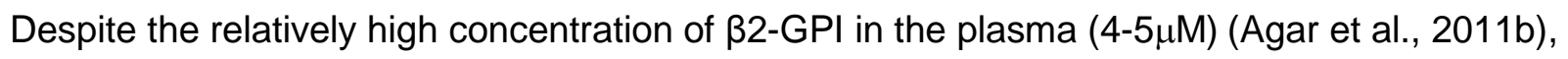
specific physiological roles for the protein are not yet well defined. However, human $\beta 2-G P I$ is clearly involved in the autoimmune diseases, anti-phospholipid syndrome and systemic lupus erythematosus (Cabiedes et al., 1995). Multiple activities have been ascribed to $\beta 2-G P I$, such as binding to cellular debris with exposed negative charges, nucleic acids, apoptotic bodies and endothelial microvesicles (Hagihara et al., 2002; Manfredi et al., 1998). Recent studies demonstrated that $\beta 2$-GPI scavenges lipopolysaccharide from the blood stream (Agar et al., 2011a; Agar et al., 2011c; Fischetti et al., 2005; Laplante et al., 2011; Meroni et al., 2001; Tolomeo et al., 2009); moreover, $\beta 2-\mathrm{GPI}$ also binds to Streptococcal protein $\mathrm{H}$ (Nilsson et al., 2008) and other pathogenic derived proteins (Stefas et al., 2011). 
As $\beta 2-$ GPI-derived peptides attenuate deposition of both $\beta 2-\mathrm{GPI}$ and anti- $\beta 2-\mathrm{GPI} A b$ in response to IR, it is possible that administration of exogenous $\beta 2$-GPI may alter IR-induced injury. As indicated in Figure 1, additional $\beta 2-$ GPI may be deposited on the cell surface leading to increased $\mathrm{Ab}$ binding, complement activation and subsequent injury (Fig. 1B). It is also possible that purification of the proteins structurally alters $\beta 2-$ GPI preventing $A b$ recognition of cell surface bound $\beta 2-$ GPI and resulting in attenuated injury (Fig. 1C). Finally, purification of $\beta 2-$ GPI may change the conformation and allow formation of soluble immunocomplexes (Fig. 1D) which precludes Ab recognition of endogenous $\beta 2$-GPI and results in attenuated IR-induced tissue injury.

We initially tested the overall hypothesis that treating with $\beta 2-\mathrm{GPI}$ would alter intestinal injury by injecting mice with purified $\beta 2-$ GPI prior to inducing Sham or IR-induced injury. Neither human $\beta 2-$ GPI nor the mouse protein exacerbated tissue damage. Surprisingly, human, but not mouse $\beta 2-\mathrm{GPI}$ protein, attenuated IR-induced tissue damage and $\mathrm{PGE}_{2}$ production, suggesting that a structural and/or physiological difference of soluble human $\beta 2$-GPI prevents IR-induced injury in the mouse. Despite possessing $76 \%$ amino acid identity and $86 \%$ sequence homology, we further demonstrate that human and mouse $\beta 2$-GPI contain distinct chemical, physical and biochemical properties which contribute to the differences observed in IR-induced injury and inflammation in the mouse. 


\section{Methods}

\subsection{Mice}

C57BI/6, Balb/c, and Rag-1 ${ }^{-1-}$ mice were obtained from Jackson Laboratories and bred in the Division of Biology at Kansas State University with free access to food and water. Mice were maintained in a specific pathogen free environment (Helicobacter species, mouse hepatitis virus, minute virus of mice, mouse parvovirus, Sendai virus, murine norovirus, Mycoplasma pulmonis, Theiler's murine encephalomyelitis virus, and endo- and ecto-parasites). Research was conducted in compliance with the Animal Welfare Act and other federal statutes and regulations relating to animals and experiments involving animals and was approved by the Institutional Animal Care and Use Committee at Kansas State University.

\subsection{Ischemia/Reperfusion}

Animals were subjected to IR similar to previously described studies (Moses et al., 2009). Briefly, ketamine $(16 \mathrm{mg} / \mathrm{kg})$ and xylazine $(80 \mathrm{mg} / \mathrm{kg})$ anesthetized male mice (2-4 months old) were administered buprenorphine $(0.06 \mathrm{mg} / \mathrm{kg})$ for pain. After laparotomy and a $30 \mathrm{~min}$ equilibration period, ischemia was induced by application of a small vascular clamp (Roboz Surgical Instruments, Gaithersburg, MD) to the isolated superior mesenteric artery. Ischemia was visually confirmed by blanching of the mid-jejunum. The bowel was covered with moistened surgical gauze to prevent desiccation. After $30 \mathrm{~min}$ of ischemia, the clamp was removed and the intestines reperfused for $2 \mathrm{~h}$. Reperfusion was confirmed by observing a pinkish color change of the bowel and the return of pulsatile flow to the mesenteric artery and its branches. Some mice received $\beta 2$-GPI (either purified or purchased from Aro Tec (Wellington, New Zealand) or Fitzgerald, (Acton, MA)) i.v. 30 min prior to ischemia. Sham-treated animals underwent the same surgical intervention without occlusion. All procedures were performed with the animals breathing spontaneously and body temperature maintained at $37^{\circ} \mathrm{C}$ using a water-circulating heating pad. Additional ketamine and xylazine was administered as needed and immediately 
prior to sacrifice. After sacrifice, $2 \mathrm{~cm}$ sections of the small intestine, $10 \mathrm{~cm}$ distal to the gastroduodenal junction were harvested for histologic evaluation and $\mathrm{PGE}_{2}$ determination.

\subsection{Histology and Immunohistochemistry}

Small intestine specimens were promptly fixed in $10 \%$ buffered formalin phosphate and embedded in paraffin, sectioned transversely $(8 \mu \mathrm{m})$, and H\&E stained. The mucosal injury score (SMI) was graded on a six-tiered scale modified from Chiu et. al. (Chiu et al., 1970). Briefly, the average damage score of the intestinal section (75-150 villi) was determined after grading each villus from 0-6. Normal villi were assigned a score of zero; villi with tip distortion were assigned a score of 1; a score of 2 was assigned when Guggenheims' spaces were present; villi with patchy disruption of the epithelial cells were assigned a score of 3; a score of 4 was assigned to villi with exposed but intact lamina propria with epithelial sloughing; a score of 5 was assigned when the lamina propria was exuding; last, villi that displayed hemorrhage or were denuded were assigned a score of 6 . Photomicrographs were obtained from H\&E stained slides using a 20X, 0.5 Plan Fluor objective on Nikon 80i microscope and images acquired at room temperature using a Nikon DS-5M camera with DS-L2 software. Additional intestinal sections were snap frozen in OCT freezing medium and $8 \mu \mathrm{m}$ cryosections cut for analysis of C3 deposition as described previously (Fleming et al., 2010). Briefly, acetone fixed slides were blocked with $10 \%$ normal donkey sera for $30 \mathrm{~min}$ at $37^{\circ} \mathrm{C}$ prior to staining with rat anti-mouse C3 Ab (Hycult Biotechnologies, Plymouth Meeting, PA) for $1 \mathrm{hr}$ at room temperature and followed by a Texas-red conjugated donkey-anti-rat IgG secondary Ab (Jackson Immunoresearch, West Grove, PA). Each experiment contained serial sections stained with the appropriate isotype control Ab. All slides were mounted with ProLong Gold (Invitrogen, Grand Island, NY). A blinded observer obtained images at room temperature using a Nikon eclipse 80i microscope equipped with a CoolSnap CF camera (Photometrics, Tucson, AZ) and analyzed using Metavue software (Molecular Devices, Sunnyvale, CA). 


\subsection{Eicosanoid and Cytokine Determination}

The ex vivo generation of eicosanoids from small intestinal tissue was determined as described previously (Sjogren et al., 1994). Briefly, fresh mid-jejunum sections were minced, washed and resuspended in $37^{\circ} \mathrm{C}$ oxygenated Tyrode's buffer (Sigma, St. Louis, MO). After incubating for 20 min at $37^{\circ} \mathrm{C}$, supernatants were collected and supernatants and tissue were stored at $-80^{\circ} \mathrm{C}$ until assayed. The concentration of prostaglandin $E_{2}\left(P E_{2}\right)$ was determined using an enzyme immunoassay kit (Cayman Chemical, Ann Arbor, MI). The tissue protein content was determined using the bicinchoninic acid assay (Pierce, Rockford, IL) adapted for use with microtiter plates. $\mathrm{PGE}_{2}$ production was expressed per mg protein per $20 \mathrm{~min}$.

\section{5 $\beta 2$-GPI Purification}

Human and mouse (C57BI/6, Balb/c or Rag-1 ${ }^{-/}$) $\beta 2-\mathrm{GPI}$ were purified using the procedure described and modified previously (Schultze, 1961; Wurm, 1984). Briefly, perchloric acid was added dropwise to ice cold mouse or human citrated plasma to a final concentration of $1.75 \%$ prior to centrifugation at $4,000 \mathrm{rpm}$ at $4^{\circ} \mathrm{C}$. The supernatant was then neutralized with saturated sodium carbonate and $1.0 \mathrm{M}$ acetic acid prior to dialyzing overnight against $30 \mathrm{mM} \mathrm{NaCl} 20 \mathrm{mM}$ Tris, $\mathrm{pH} 8.0$, at $4^{\circ} \mathrm{C}$ with at least 2 buffer changes. The dialyzed solution was applied to a HiTrap Heparin HP column (ThermoFisher, USA), washed with dialysis buffer and eluted with 175-200 $\mathrm{mM} \mathrm{NaCl} 20 \mathrm{mM}$ Tris, $\mathrm{pH} 8.0$.

\subsection{Molecular Weight Analysis of $\beta 2-$ GPI}

MALDI-TOF MS was performed on a Bruker Ultraflex II TOF/TOF mass spectrometer. Molecular weight of purified $\beta 2-$ GPI was analyzed in the positive mode. Sinapinic acid was used as a matrix. MS spectra were recorded in linear mode within a mass range from $\mathrm{m} / \mathrm{z} 10,000$ to m/z 70,000 and externally calibrated using a protein mass standard kit II (Bruker Daltonics, Billerica, MA). 


\subsection{Proteomics Analysis Using In Gel Digestion:}

Coomassie brilliant blue stained and excised gel pieces were destained by several 10 min incubations in $100 \mu \mathrm{L}$ of $50 \%$ acetonitrile $(\mathrm{ACN})$ at $30^{\circ} \mathrm{C}$. After destaining, reduction and alkylation of cysteine residues was accomplished with Tris[2-carboxyethyl]phosphine (TCEP) and lodoacetamide followed by the supplier protocol (\#8971 in gel trypsin digestion kit, Thermo Scientific, USA). After washing the gels with 50\% ACN, 100\% ACN (50 $\mu \mathrm{L})$ was added for 10 min at $30^{\circ} \mathrm{C}$ to shrink the gel pieces. After discarding the solvent and drying by speed vacuum concentration, the gel plugs were rehydrated in $20 \mu \mathrm{L}$ of sequencing grade trypsin (200 ng; Trypsin Gold, Promega, Madison, WI) in 20 mM ammonium bicarbonate. Upon rehydration, the gel plugs were incubated in an additional $20 \mu \mathrm{L}$ of $20 \mathrm{mM}$ ammonium bicarbonate with $10 \%$ $\mathrm{ACN}$ at $30^{\circ} \mathrm{C}$ for $17 \mathrm{~h}$. Tryptic peptides were extracted from the gel plugs with $100 \mu \mathrm{L}$ of $50 \%$ ACN containing $2 \%$ trifluoroacetic acid (TFA) at $30^{\circ} \mathrm{C}$ for $30 \mathrm{~min}$. Extracted peptides were concentrated by speed vacuum concentration.

\subsection{Nano-HPLC and Electrospray Ionization Tandem Mass Spectrometry (ESI-MS/MS)}

Nano-HPLC was performed automatically using a microcolumn switching device (Switchos; LC Packings) coupled to an autosampler (Famos: LC Packings) and a nanogradient generator (UltiMate Nano HPLC; LC Packings). Peptide solution (30 $\mu \mathrm{L})$ was loaded on a C18 reversedphase capillary column (75 $\mu \mathrm{m}$ ID $\times 15 \mathrm{~cm}$, PepMap: Dionex) in conjunction with an Acclaim C18 PepMap trapping column (300 $\mu \mathrm{m}$ id $\times 10 \mathrm{~mm}$, Dionex). Peptides were separated by a nanoflow linear ACN gradient using buffer $A(0.1 \%$ formic acid, $2 \% A C N)$ and buffer $B(0.1 \%$ formic acid, $80 \%$ ACN) starting from $5 \%$ buffer B to $70 \%$ over 55 min at a flow rate of 200 $\mathrm{nL} / \mathrm{min}$. Then column was washed by $95 \%$ of buffer B for 5 min. The system control software, Hystar 3.2, was used to control the entire process. The eluted peptides were injected into an HCT Ultra Ion Trap Mass Spectrometer (Bruker Daltronics). The mass spectrometer was set up 
in the data dependent MS/MS mode to alternatively acquire full scans ( $\mathrm{m} / \mathrm{z}$ acquisition range from 300 to 1,700 Da). The four most intense peaks in any full scan were selected as precursor ions and fragmented by collision energy. MS/MS spectra were interpreted and peak lists were generated by DataAnalysis 3.4 and Biotools 3.0 software (Bruker Daltronics).

\subsection{Bioinformatics}

Peptide masses were compared to Swiss Prot Database using MASCOT 2.2

(http://www.matrixscience.com). Human or mouse genomes were selected for the taxonomy search. The following parameters were used in all searches: the maximum number of missed cleavages allowed was 2; the mass tolerance was 0.6 Da for MS and 0.6 Da for MS/MS. Fixed modification was set on cysteine with carbamidomethylation. Variable modification was based on methionine with oxidation. Positive protein identifications using a threshold of 0.05 were used. Peptides scoring <20 were automatically rejected, ensuring all protein identifications were based on the reliable peptide identifications.

\subsection{Fluorescence Spectroscopy}

Fluorescence emission scans were recorded in a Cary Eclipse fluorescence spectrophotometer (Varian Inc., Palo Alto, CA). To eliminate background fluorescence from tyrosine residues, spectra were collected by exciting the sample at $295 \mathrm{~nm}$. Scans were collected at a scan rate of $60 \mathrm{~nm} / \mathrm{min}$ in a $0.3 \mathrm{~cm}$ path length quartz cuvette (Starna Cells, Inc., Atascadero, CA) with the emission slit width set to $5 \mathrm{~nm}$. All scans were collected at room temperature and data plotted in SigmaPlot (Systat, San Jose, CA).

\subsection{Circular Dichroism (CD) Spectroscopy}

CD spectra were collected in a Jasco J-815 CD spectrophotometer (Jasco Analytical Instruments, Easton, MD) using a $0.02 \mathrm{~cm}$ path length circular quartz cuvette (Hellma USA, 
Plainview, NY). Samples were scanned from $320 \mathrm{~nm}$ to $190 \mathrm{~nm}$ at room temperature. The final spectrum for each sample was an average of eight scans recorded at a scan rate of $50 \mathrm{~nm} / \mathrm{min}$ with a $0.1 \mathrm{~nm}$ step interval and measured in mdeg. Raw scans were processed (subtracted from blank and smoothed) using Spectra Analysis (software provided by Jasco Inc.) and converted to mean residue ellipticity using the following equation: $[\theta]=\frac{100(\text { signal })}{C n l}$ where, $[\theta]$ is the mean residue ellipticity in deg $\mathrm{cm}^{2} \mathrm{dmol}^{-1}$; signal is the raw output in mdeg; $C$ is protein concentration in $\mathrm{mM} ; n$ is number of residues and $l$ is cell pathlength in $\mathrm{cm}$. The final spectra were plotted in SigmaPlot.

\subsection{D SDS-PAGE}

Purified $\beta 2-\mathrm{GPI}$ (190 $\mu \mathrm{g}$ and $170 \mu \mathrm{g}$ for the human and mouse proteins, respectively) were applied to an $11 \mathrm{~cm}$ IPG strip with a pH 3-10 gradient (Bio-Rad), for overnight passive rehydration at $25^{\circ} \mathrm{C}$. Strips were focused at $20^{\circ} \mathrm{C}$ with the following program: 20 min with a linear ramp (0-250 V), $2.5 \mathrm{~h}$ with a linear ramp (250-8,000 V), 20,000 V h with a rapid ramp (8,000 V). Once the IEF was completed, the strips were equilibrated in Equilibration Buffer I (6 M urea, 2\% SDS, 0.375 Tris- $\mathrm{HCl}$ (pH 8.8), 20\% glycerol, and 2\% (w/v) DTT) (Bio-Rad) followed by another 15 min in Equilibration Buffer II (Equilibration Buffer I containing 2.5\% iodoacetamide in place of DTT) (Bio-Rad). 1\% agarose solution with $0.01 \%$ bromophenol blue was laid on the top of gels to protect the strip. SDS-PAGE was performed using a 10\% Criterion Tris- $\mathrm{HCl}$ Precast Gel (Bio-Rad). The second dimension was run at $150 \mathrm{~V}$ until the bromophenol blue dye front completely migrated out of the bottom of the gel. The gels were stained with Bio-Safe Coomassie Brilliant Blue G-250 (Bio-Rad).

\subsection{Anti- $\beta 2-$-GPI ELISA}

Polystyrene microtiter plates were coated overnight with $8 \mu \mathrm{g} / \mathrm{mL}$ mouse or human $\beta 2-\mathrm{GPI}$ in 0.02M carbonate buffer, $\mathrm{pH}$ 9.6. Purified mouse and human Ig were applied to appropriate wells 
at $1 \mathrm{mg} / \mathrm{mL}$, with an anti-mouse $\beta 2$-GPI monoclonal Ab (FC1) (Fleming et al., 2004) and goat anti-human $\beta 2$-GPI Ab(Bethyl Labs, Montgomery, TX) used as positive controls, for $1 \mathrm{~h}$ at room temperature. After washing, appropriate HRP-conjugated secondary Ab (Jackson Immunoresearch) were then applied for $1 \mathrm{~h}$ at room temperature and developed using TMB 1Component substrate (KPL, Gaithersburg, MD).

\subsection{Immunoprecipitation}

PureProteome Protein G magnetic beads (Millipore) were coated with antibody from C57BI/6 mice prior to adding $4 \mathrm{uM}$ purified $\beta 2-\mathrm{GPI}$ and incubating overnight at $4^{\circ} \mathrm{C}$. The beads were washed and bound $\beta 2$-GPI was eluted per manufacturer's directions. Samples were analyzed on $10 \%$ SDS-PAGE and Western blotted for $\beta 2$-GPI using HRP-goat anti-human $\beta 2-$ GPI or antimouse IgG antibody.

\subsection{Statistics}

All data were evaluated by one-way ANOVA with Newman-Keuls post hoc analysis (GraphPad/Instat Software) and are presented as mean \pm SEM. 


\section{Results}

\subsection{Human but not mouse $\beta 2-$ GPI attenuates IR-induced intestinal injury in a dose dependent manner.}

Previous studies strongly support the view that $\beta 2-\mathrm{GPI}$ is involved in one of the sequential events leading to IR-induced injury (Fleming et al., 2004). In fact, peptides derived from the $\beta 2$ GPI lipid binding domain (domain 5) inhibit IR-induced complement deposition and subsequent intestinal damage and inflammation (Fleming et al., 2010). Initial ELISA data confirmed the presence of significantly more $\beta 2$-GPI-Ab complexes within tissues from IR-treated mice $(748 \pm$ 97 relative units) than within tissues from Sham treated animals (233 \pm 65 relative units). As the $\beta 2-G P I-A b$ complexes were limited in uninjured tissue, these studies suggested that treatment with exogenous $\beta 2$-GPI may provide additional antigen for increased Ab binding (Fig. 1B) and could exacerbate intestinal injury and inflammation.

To understand the specific role of $\beta 2$-GPI in IR-induced tissue damage, we tested the hypothesis by treating wildtype, C57BI/6 mice with purified human or mouse $\beta 2-\mathrm{GPI}$ immediately prior to subjecting the mice to Sham or IR. As expected, IR induced significant injury when compared to Sham treatment (Fig. 2A, B, C). However, mouse $\beta 2-$ GPI derived from either Rag1 ${ }^{-1-}$, C57BI/6 or Balb/c mice did not significantly alter IR-induced injury (Fig. 2A, E and data not shown). Surprisingly, human $\beta 2-$ GPI significantly inhibited IR-induced intestinal injury (Fig. 2A, F) with a mean injury score of $1.44 \pm 0.16$ compared to $2.33 \pm 0.17$ in saline-treated mice. Additional studies demonstrated that human $\beta 2-$ GPI attenuated intestinal injury in a dose dependent manner (Fig. 3A). Administration of either 40 or $200 \mu \mathrm{g} / \mathrm{kg} \beta 2-\mathrm{GPI}$ prior to IR significantly decreased injury (Fig. 3A). However, $20 \mu \mathrm{g} / \mathrm{kg}$ human $\beta 2-\mathrm{GPI}$ did not attenuate IRinduced intestinal injury. Two different commercial preparations of human $\beta 2-\mathrm{GPI}$ showed similar results with IR-induced injury scores of $1.17 \pm 0.22$ and $0.93 \pm 0.23$ (Arotec, Wellington, 
New Zealand and Fitzgerald, Acton, MA, respectively). Thus, human, but not mouse, $\beta 2-$ GPI attenuates IR-induced intestinal injury in a dose dependent manner.

\subsection{Human $\beta 2-$ GPI attenuated $\mathrm{PGE}_{2}$ and complement deposition}

To examine the mechanism of protection from injury, $\mathrm{PGE}_{2}$ production and complement deposition were analyzed. Similar to injury, intestinal PGE $_{2}$ production was significantly elevated after IR in the presence or absence of mouse $\beta 2$-GPI (Fig. 3B). However, only Sham levels of intestinal $\mathrm{PGE}_{2}$ were produced in mice treated with human $\beta 2-\mathrm{GPI}$ prior to IR (Fig. 3B). PGE 2 production also decreased in a dose dependent manner after administration of human $\beta 2-\mathrm{GPI}$ (Fig. 3B). Administering $40 \mu \mathrm{g} / \mathrm{kg}$ human $\beta 2-\mathrm{GPI}$ attenuated $\mathrm{PGE}_{2}$ production, and $200 \mu \mathrm{g} / \mathrm{kg}$ prior to IR produced $\mathrm{PGE}_{2}$ concentrations comparable to Sham treatment (Fig. 3B) indicating that $200 \mu \mathrm{g} / \mathrm{kg}$ optimally inhibits both injury and PGE 2 production.

As complement is required for IR-induced tissue damage, we examined C3 deposition. Complement deposition was observed in response to IR but not on intestines of Sham treated mice. Similar to $\mathrm{PGE}_{2}$ and injury, C3 deposition significantly decreased after treatment with human $\beta 2-$ GPI when compared to mice subjected to IR only (Fig. 4). Treatment with mouse $\beta 2-$ GPI reduced complement deposition slightly but not to the same extent as treatment with human $\beta 2-$ GPI (Fig. 4). Thus, human $\beta 2-$ GPI attenuated IR-induced injury and inflammation as

determined by $\mathrm{PGE}_{2}$ production and complement deposition. Together, these data suggest that human and mouse $\beta 2$-GPI interact differently in the mouse model of IR-induced tissue damage.

\subsection{Human $\beta 2-$ GPI is recognized by mouse antibodies}

$A s \mathrm{Ab}$ are required for complement activation in the current model of IR-induced tissue injury, it is possible that mouse $\mathrm{Ab}$ does not recognize surface-bound, human $\beta 2-\mathrm{GPI}$ in the same way 
as endogenous $\beta 2-$ GPI (Fig. 1C). ELISAs performed with purified human and mouse proteins measured the binding of native Ab with each protein. As expected, optimal Ab recognition of $\beta 2-$ GPI was species specific (Fig. 5A). However, Ab purified from mouse plasma clearly recognized bound human $\beta 2-$ GPI as well (open bar). In addition, Ab purified from human plasma recognized bound mouse $\beta 2-\mathrm{GPI}$ (black bar). Together these data indicate that mouse Ab are capable of binding surface-bound, human $\beta 2-\mathrm{GPI}$ (Fig 5A) and suggests that the human $\beta 2-\mathrm{GPI}$ may compete with mouse $\beta 2-\mathrm{GPI}$ for Ab recognition.

As $\beta 2-$ GPI changes conformation when bound to a surface, it was possible that soluble human and mouse $\beta 2-$ GPI were recognized differently. To determine if soluble human or mouse $\beta 2-$ GPI was bound by mouse Ab similar to bound $\beta 2-$ GPI, we immunoprecipitated the two $\beta 2-$ GPI preparations with mouse Ab. As indicated in Figure 5B, soluble human $\beta 2-$ GPI bound to beads coated with antibodies from C57BI/6 mice (Lane 4). Surprising, no or very little soluble mouse $\beta 2-$ GPI bound to the mouse anti- $\beta 2-$ GPI-coated beads (Lanes 2-3). However, mouse $\beta 2-\mathrm{GPI}$ was detectable in the supernatants (data not shown). Equal quantities of Ab were bound to the beads as indicated in the lower panel. Thus, mouse Ab appear to bind soluble human but not mouse $\beta 2-\mathrm{GPI}$, suggesting that administration of human $\beta 2-\mathrm{GPI}$ reduces the $\mathrm{Ab}$ available for binding the conformationally altered, surface-bound, mouse $\beta 2-\mathrm{GPI}$. Together, these data support the hypothesis illustrated in Figure 1D.

\subsection{Physical and biochemical differences in human and mouse $\beta 2-\mathrm{GPI}$.}

It is possible that IR-induced injury was attenuated after treatment with human protein due to structural differences in the two proteins that prevented binding of human $\beta 2-\mathrm{GPI}$ to the cell surface as suggested in Figure 1D. We examined the physical and biochemical properties of similarly purified mouse and human $\beta 2-$ GPI. In the presence of thiol reducing agents, SDS- 
PAGE demonstrated that the two glycoproteins were more than 95\% pure with an apparent molecular weight of $58 \mathrm{kDa}$ for the mouse protein and $54 \mathrm{kDa}$ for the human (Supplementary Fig. 1, lanes 1 and 2, respectively). Proteomics analysis confirmed the identity of the two purified proteins, namely mouse (APOH_MOUSE) and human (APOH_HUMAN) $\beta 2-\mathrm{GPI}$. TOFMS spectrometry analysis verified the molecular weight difference of the intact proteins. Figure $6 \mathrm{~A}$ illustrates the mass difference with a relatively broad peak centered at $48 \mathrm{kDa}$ for mouse $\beta 2$ GPI (gray line) while the human protein (black line) presents a narrower peak, centered at 45 kDa. Since the MALDI TOF-MS peak width is strictly correlated to the sample heterogeneity, we examined the nature of the glycosylation patterns. The mouse protein was N-glycosylated at Asn residues 162, 183, 193 and 253 (sequence number was followed by registered sequence at Swiss-plot). Human protein possessed a different pattern being N-glycosylated at Asn residues 105, 117, 183 and 193 (Supplementary Fig. 2). PNGase F (Glycopeptidase F) treatment significantly decreased that molecular weights from $58 \mathrm{kDa}$ to $36.5 \mathrm{kDa}$ for the mouse protein and from $54 \mathrm{kDa}$ to $38 \mathrm{kDa}$ for the human, providing further evidence of glycosylation differences between the two species (Supplementary Fig. 1, lanes 3-6). The increased heterogeneity was confirmed by 2D gel electrophoresis which indicated 10 distinct spots with the same molecular weight spanning from pl 5.6 to 7.9 (Fig. 6B). In contrast, the human protein (Fig. 6C) contained only 8 spots ranging from pl 6.0 to 7.5 . Thus, despite $76 \%$ amino acid identity and $86 \%$ sequence similarity, the two proteins possess small but significant differences in heterogeneity.

To further examine the structural differences between mouse and human $\beta 2-\mathrm{GPI}$, we analyzed the samples using fluorescence spectroscopy and circular dichroism. Fluorescence spectroscopy at $295 \mathrm{~nm}$ examined the environment surrounding the tryptophans located at identical positions in the primary sequence. Figure 7A shows that the fluorescence emission 
spectrum for each protein is a single peak with a maximum emission at a wavelength of $341 \mathrm{~nm}$ for the mouse $\beta 2-\mathrm{GPI}$ (dashed line) and at $349 \mathrm{~nm}$ for the human protein (solid line). A significant shift towards the lower wavelengths indicates that in the mouse $\beta 2-\mathrm{GPI}$ folded structure the tryptophan residues are significantly less solvent exposed compared to the same residues in the human $\beta 2-\mathrm{GPI}$. Circular dichroism confirmed that mouse and human $\beta 2-\mathrm{GPI}$ were structurally different with human $\beta 2-$ GPI being less ordered in the far UV region compared to mouse $\beta 2-$-GPI (Fig. 7B). These data provide strong evidence for two distinct conformations for the isolated mouse and human proteins that influence IR-induced injury when administered to wildtype mice.

\section{Discussion}

Although the $\beta 2$-GPI protein was discovered in human plasma 50 years ago, the specific physiological roles remain unknown. $\beta 2-$ GPI does appear to scavenge lipopolysaccharide and inhibit complement activation (Gropp et al., 2011) and thereby plays a role in the innate immune response (Agar et al., 2011c; Gropp et al., 2011). The structural homology is quite conserved among mammalian species and can reach $90-98 \%$ sequence identity in specific segments located at the C-terminus where the binding with anionic lipids occurs. Given the homology, most in vivo mouse studies for anti-phospholipid syndrome utilize commercially available human anti-ß2-GPI Ab or human $\beta 2-G P I$ (Agostinis et al., 2011; Fleming et al., 2004). We purified human and mouse $\beta 2-\mathrm{GPI}$ and compared the biological response of the two proteins in the mouse intestinal IR model. Biochemically, the two species of protein contain significant structural differences. Compared to the human protein, we demonstrated that mouse $\beta 2-\mathrm{GPI}$ has an increased molecular weight, increased number of isoforms and differential glycosylation pattern. In addition, the environment surrounding the 5 tryptophan residues, one for each domain, is considerably less solvent accessible in the mouse versus the human protein. Importantly, mouse $\mathrm{Ab}$ bound and immunoprecipitated soluble human but not mouse $\beta 2-\mathrm{GPI}$ 
suggesting that the structural differences allow human $\beta 2-\mathrm{GPI}$ to sequester mouse anti- $\beta 2-\mathrm{GPI}$ $A b$ and attenuate IR-induced injury and inflammation in the mouse.

Although injury and complement deposition were significantly attenuated after the addition of the human protein, both remained significantly higher than in Sham animals. Complement inhibitors demonstrated a similar degree of attenuation (Rehrig et al., 2001) and suggest that human $\beta 2-$ GPI may contain complement inhibitory activity when employed in mouse models of disease. $\beta 2-$ GPI contains multiple short consensus repeats of the complement control protein family and recent studies demonstrated complement inhibitory effects in vitro. Human $\beta 2-$ GPI contains a $\mathrm{C} 3 / \mathrm{C} 3 \mathrm{~b}$ binding site which upon binding alters the $\mathrm{C} 3 / \mathrm{C} 3 \mathrm{~b}$ conformation, allows Factor $\mathrm{H}$ binding and inhibits subsequent complement activation (Gropp et al., 2011). This finding supports the current finding in which human $\beta 2-\mathrm{GPI}$ attenuates mouse $\mathrm{C} 3$ deposition in the mouse model of intestinal IR. While a C3 binding site has not been identified in the mouse protein, it is plausible that the human $\beta 2-\mathrm{GPI}$ may be more effective in binding to $\mathrm{C} 3 / \mathrm{C} 3 \mathrm{~b}$ or that mouse $\beta 2-\mathrm{GPI}$ binding to $\mathrm{C} 3 / \mathrm{C} 3 \mathrm{~b}$ does not expose the Factor $\mathrm{H}$ binding site. Either possibility would allow the complement cascade to continue in the presence of mouse but not human $\beta 2$ GPI.

In contrast to complement deposition and injury, treatment with human $\beta 2-\mathrm{GPI}$ inhibited intestinal $P G E_{2}$ secretion to background levels, suggesting that the pathway to $\mathrm{PGE}_{2}$ production is more sensitive to the conformational changes of $\beta 2-\mathrm{GPI}$ than overall injury. The IR-induced production of $\mathrm{PGE}_{2}$ is dependent on both TLR4 and Ab interactions (Moses et al., 2009; Pope et al., 2010; Sparkes et al., 2010). An in vitro study recently demonstrated that human $\beta 2$-GPI/antiß2-GPI Ab forms complexes with TLR4 to activate endothelial cells (Allen et al., 2011). 
Therefore, it is possible that the complex formation of human $\beta 2$-GPI with mouse $A b$ is not as efficient in activating endothelial cells to produce $\mathrm{PGE}_{2}$.

It is likely that administration of human but not mouse $\beta 2-\mathrm{GPI}$ attenuated IR-induced injury by formation of human $\beta 2-\mathrm{GPI} /$ mouse $\mathrm{Ab}$ complexes in the serum which reduced $\mathrm{Ab}$ binding of endogenous $\beta 2-\mathrm{GPI}$ and subsequent injury and $\mathrm{PGE}_{2}$ production. Although mouse Ab do not recognize surface-bound human $\beta 2-\mathrm{GPI}$ as effectively as mouse $\beta 2-\mathrm{GPI}$, mouse Ab recognized soluble human $\beta 2-$ GPI significantly better than mouse $\beta 2-$ GPI. These data suggest that human $\beta 2-\mathrm{GPI} / \mathrm{mouse}$ Ab complexes may indeed form in the mouse. Previous studies also indicated that immunization of mice with human $\beta 2-$ GPI produced Ab which induced fetal resorption presumably by recognition of mouse $\beta 2-$ GPI (Agostinis et al., 2011). Together these data suggest that the human $\beta 2-$ GPI binding to mouse tissue may differ from mouse $\beta 2-$ GPI binding and tissue activation state may be important.

Biochemical analysis of the human and mouse $\beta 2$-GPI suggest a number of possibilities for the observed biological differences. 2D electrophoresis indicated multiple isoforms, similar to a previous report of commercially available human $\beta 2$-GPI (Buttari et al., 2005). Although the amino acid composition of $\beta 2-\mathrm{GPI}$ indicates that the mouse protein is more basic (theoretical $\mathrm{pl}$ $=8.62$ ) than the human protein (theoretical $\mathrm{pl}=8.37$ ), $2 \mathrm{D}$ gel analysis shows that the average actual pl of the mouse protein is more acidic suggesting that the amino acid differences are compensated by negative charges introduced through post-translational modifications. The human native $\beta 2$-GPI is decorated with a variable number of sialic acid residues (Kondo et al., 2009; Schousboe, 1983). The addition of variable numbers of sialic acid residues and/or other carbohydrate chains would explain the multiple isoforms found on the $2 \mathrm{D}$ gel. Although this explanation is in agreement with previous human protein studies (Gries et al., 1989; Schousboe, 
1983), our data do not exclude the possibility that the altered pl is derived from other sources including partial deamination of glutamine or asparagine residues.

Additional biochemical measures, fluorescent spectra and circular dichroism, indicated differences in the folded states of the proteins. The wavelength of the fluorescence emission peak of the mouse protein is significantly lower than that of the human protein, suggesting the tryptophans residues are not exposed in the mouse $\beta 2-\mathrm{GPI}$. In addition, circular dichroism studies on the human protein are reminiscent of previous studies performed with the human $\beta 2$ GPI, which contain a weak negative at $195 \mathrm{~nm}$ (Lee et al., 1983). However, we showed that the mouse $\beta 2-$-GPI contained a significant negative peak centered around $208 \mathrm{~nm}$ suggesting a conformational change. Thus, fluorescence, circular dichroism and overall carbohydrate data suggest a different or dynamic structural environment with exposure of different surface residues which are critical to interaction with other proteins. These changes appear to influence the activation of the inflammatory cascade which mediates IR-induced intestinal injury. 


\section{Acknowledgements}

We would like to thank Mr. Andrew Fritze for technical assistance with immunohistochemistry and PGE 2 assays. This work was supported by NIH grant Al061691 (SDF) and P20 RR017686 (SDF), and RR016475 (SDF) from the Institutional Development Award Program of the National Center for Research Resources and the Johnson Center for Basic Cancer Research (SDF). Support for the project was also made possible in part by a KSU Targeted Excellence Award (JMT) and an NSF Major Research Instrumentation Program Grant No. 0521587 (JMT). 


\section{Figure Legend}

Figure 1: Hypothetical models of exogenous $\beta 2-\mathrm{GPI}-\mathrm{Ab}$ interactions. Under normal conditions, the closed conformation of soluble $\beta 2-\mathrm{GPI}$ is not recognized by anti- $\beta 2-\mathrm{GPI} A b(\mathrm{~A})$. During IRinduced stress, membrane lipid alterations allow Ab recognition of bound $\beta 2-\mathrm{GPI}$ (mouse protein is dark, human protein is light) and induces injury which may be exacerbated by exogenous $\beta 2$ GPI (B). Excess $\beta 2-$ GPI may bind to altered lipids without Ab recognition (C) or exogenous $\beta 2$ GPI may form soluble immunocomplexes resulting in attenuated IR-induced injury (D).

Figure 2: Human but not mouse $\beta 2-\mathrm{GPI}$ treatment alters IR-induced injury and $\mathrm{PGE}_{2}$ production in C57BI/6 mice. C57BI/6 mice were subjected to Sham or IR treatment in the presence or absence of $\beta 2-$ GPI purified from Balb/c (Balb B2), Rag-1-/- (Rag-1-/- B2) or Human (Human B2) plasma. Two hours after initiation of reperfusion, mid-jejunal intestinal sections (75-150 villi per animal) were scored (A) and ex vivo $\mathrm{PGE}_{2}(\mathrm{D})$ production were assessed. Representative H\&E stained tissue sections (200X) are provided (B, C, E, F). PGE 2 values are represented as pg/mg of intestinal protein. Each bar represents 4-10 animals. * $=p \leq 0.05$ compared to Sham + peptide, $\phi=p \leq 0.05$ compared to I/R treatment animals not receiving peptides.

Figure 3: Human $\beta 2-\mathrm{GPI}$ attenuates IR-induced intestinal damage and $\mathrm{PGE}_{2}$ production in a dose dependent manner. Mouse $\beta 2-\mathrm{GPI}(200 \mu \mathrm{g} / \mathrm{kg})$ or Human $\beta 2-\mathrm{GPI}(\mathrm{H})$ at 200,40 or 20 $\mu \mathrm{g} / \mathrm{kg}$ was administered prior to subjecting C57BI/6 mice to Sham or IR treatment. Two hours after initiation of reperfusion, mid-jejunal intestinal sections (75-150 villi per animal) were scored (A) and ex vivo $\mathrm{PGE}_{2}$ (B) production were assessed. Each bar represents 4-10 animals. * $=p \leq$ 0.05 compared to Sham, $\phi=p \leq 0.05$ compared to I/R treatment animals not receiving $\beta 2-G P I$.

Figure 4: Human $\beta 2-\mathrm{GPI}$ attenuates IR-induced complement deposition. C57BI/6 mice were 
subjected to Sham or IR treatment in the presence or absence of $200 \mu \mathrm{g} / \mathrm{kg} \beta 2-\mathrm{GPI}$ purified from C57BI/6 (+B6 B2) or Human (+Human B2) plasma. Two hours after initiation of reperfusion, mid-jejunal intestinal sections were collected and stained for C3 deposition. Photomicrographs represent 3 experiments of 5-7 photos per treatment group.

Figure 5: Native mouse antibodies complex with soluble and bound human $\beta 2-$ GPI but only with bound mouse $\beta 2$-GPI. (A) Mouse (left) or Human (right) purified $\beta 2-\mathrm{GPI}$ coated plates were incubated with $A b$ obtained from naïve C57Bl/6 mice (B6 Ab) or Human sera (human $A b)$ and developed with TMB to determine optical density. Each bar represents 4 samples and each graph is representative of 3 independent experiments. (B) Protein G purified C57BI/6 Ab immunoprecipitation of no $\beta 2-$ GPI (lane 1) or 21 ng of soluble Rag-1-/- (lane 2), C57BI/6 (lane 3), or human (lane 4) $\beta 2$-GPI was followed by western blot with anti-human $\beta 2$-GPI (upper panel) or anti-mouse IgG (lower panel). Western blot is representative of 3 immunoprecipitations.

Figure 6: Mouse $\beta 2-\mathrm{GPI}$ is different molecular weight and contains additional isoforms of $\beta 2-$ GPI compared to the similarly purified human protein. (A) Molecular weights of purified $\beta 2-$ GPI's were analyzed by MALDI-TOF in the positive mode using sinapinic acid as a matrix. MS spectra were recorded in linear mode within a mass range from $\mathrm{m} / \mathrm{z} 10,000$ to $\mathrm{m} / \mathrm{z} 70,000$. The scans for both purified human (black) and mouse (gray) are shown. (B, C) Purified mouse (B) or human (C) $\beta 2$-GPI were subjected to 2D SDS-PAGE and stained with coomassie blue. Mouse $\beta 2-$ GPI contains additional isoforms of $\beta 2-$ GPI protein compared to the similarly purified human protein. Gels are representative of 2 experimental preparations.

Figure 7: Fluorescence spectroscopy and circular dichroism spectroscopy indicate 
conformational differences in human and mouse $\beta 2-$ GPI. Purified human (solid line) or mouse (dashed line) $\beta 2$-GPI were subjected to fluorescence spectroscopy at excitation 295nm (A) and circular dichroism from 320 to $190 \mathrm{~nm}(\mathrm{~B})$. Mouse $\beta 2-\mathrm{GPI}(0.75 \mathrm{mg} / \mathrm{mL})$ and human $\beta 2-\mathrm{GPI}$ $(0.8066 \mathrm{mg} / \mathrm{mL})$ were normalized for comparison.

Supplemental Figure 1: SDS-PAGE analysis of mouse and human $\beta 2-$ GPI. Purified mouse (lanes $1,3,4)$ and human $(2,5,6) \beta 2-$ GPI were treated with (lanes 4,6 ) or without PNGase F and then analyzed on reduced $12 \%$ SDS-PAGE. The molecular mass (in kDa) of the standard are indicated. Representative of 2-3 gels.

Supplemental Figure 2: Primary sequence alignment of human and mouse $\beta 2-\mathrm{GPI}$ proteins. Primary sequences of human and mouse $\beta 2-\mathrm{GPI}$ proteins were aligned with NCBI Blast software. Black underline shows the peptide sequences identified by proteomics analysis. Selected asparagine residues (red) were projected N-glycosylated sites based on an Asn-X-Ser/Thr motif (X: any amino acid except for proline). 
References

Agar C., de Groot P. G., Marquart J. A. and Meijers J. C., 2011a. Evolutionary conservation of the lipopolysaccharide binding site of beta2-glycoprotein I. Thromb Haemost 106, 1069-75.

Agar C., de Groot P. G., Morgelin M., Monk S. D., van Os G., Levels J. H., de Laat B., Urbanus R. T., Herwald H., van der Poll T. and Meijers J. C., 2011b. \{beta\}2-Glycoprotein I: a novel component of innate immunity. Blood 117, 6939-47.

Agar C., de Groot P. G., Morgelin M., Monk S. D., van Os G. M., Levels J. H., de Laat B., Urbanus R. T., Herwald H., van der Poll T. and Meijers J. C., 2011c. \{beta\}2-glycoprotein I: a novel component of innate immunity. Blood.

Agar C., van Os G. M., Morgelin M., Sprenger R. R., Marquart J. A., Urbanus R. T., Derksen R. H., Meijers J. C. and de Groot P. G., 2010. \{beta\}2-Glycoprotein I can exist in two conformations: implications for our understanding of the antiphospholipid syndrome. Blood 116, 1336-1343.

Agostinis C., Biffi S., Garrovo C., Durigutto P., Lorenzon A., Bek A., Bulla R., Grossi C., Borghi M. O., Meroni P. and Tedesco F., 2011. In vivo distribution of beta2 glycoprotein I under various pathophysiologic conditions. Blood 118, 4231-8.

Allen K. L., Fonseca F. V., Betapudi V., Willard B., Zhang J. and McCrae K. R., 2011. A novel pathway for human endothelial cell activation by antiphospholipid/anti-beta2 glycoprotein I antibodies. Blood 119, 884-93.

Austen W. G., Kyriakides C., Favuzza J., Wang Y., Kobzik L., Moore F. D. and Hechtman H. B., 1999. Intestinal ischemia-reperfusion injury is mediated by the membrane attack complex. Surgery 126, 343-348.

Avrameas S., 1991. Natural autoantibodies: from 'horror autotoxicus' to 'gnothi seauton'. Immunology Today 12, 154-159.

Balasubramanian K., Chandra J. and Schroit A. J., 1997. Immune clearance of phosphatidylserineexpressing cells by phagocytes. The role of beta2-glycoprotein I in macrophage recognition. J. Biol. Chem. 272, 31113-7.

Balasubramanian K., Maiti S. N. and Schroit A. J., 2005. Recruitment of beta-2-glycoprotein 1 to cell surfaces in extrinsic and intrinsic apoptosis. Apoptosis 10, 439-46.

Bouma B., de Groot P. G., van den Elsen J. M., Ravelli R. B., Schouten A., Simmelink M. J., Derksen R. H., Kroon J. and Gros P., 1999. Adhesion mechanism of human beta(2)-glycoprotein I to phospholipids based on its crystal structure. Embo J 18, 5166-74.

Buttari B., Profumo E., Mattei V., Siracusano A., Ortona E., Margutti P., Salvati B., Sorice M. and Rigano R., 2005. Oxidized beta2-glycoprotein I induces human dendritic cell maturation and promotes a Thelper type 1 response. Blood 106, 3880-7.

Cabiedes J., Cabral A. R. and Alarcon-Segovia D., 1995. Clinical manifestations of the antiphospholipid syndrome in patients with systemic lupus erythematosus associate more strongly with anti-beta 2-glycoprotein-I than with antiphospholipid antibodies. J. Rheumatol. 22, 1899-906.

Chen J., Crispin J. C., Dalle Lucca J. and Tsokos G. C., 2009. A Novel Inhibitor of the Alternative Pathway of Complement Attenuates Intestinal Ischemia/Reperfusion-Induced Injury. J Surg Res.

Chiu C.-J., McArdle A. H., Brown R., Scott H. J. and Gurd F. N., 1970. Intestinal mucosal lesion in low-flow states. I. A morphological, hemodynamic, and metabolic reappraisal. Arch Surg. 101, 478-483.

Fischetti F., Durigutto P., Pellis V., Debeus A., Macor P., Bulla R., Bossi F., Ziller F., Sblattero D., Meroni P. and Tedesco F., 2005. Thrombus formation induced by antibodies to beta2-glycoprotein I is complement dependent and requires a priming factor. Blood 106, 2340-6. 
Fleming S. D., Egan R. P., Chai C., Girardi G., Holers V. M., Salmon J., Monestier M. and Tsokos G. C., 2004. Anti-phospholipid antibodies restore mesenteric ischemia/reperfusion-induced injury in complement receptor 2/complement receptor 1-deficient mice. J. Immunol. 173, 7055-61.

Fleming S. D., Pope M. R., Hoffman S. M., Moses T., Bukovnik U., Tomich J. M., Wagner L. M. and Woods K. M., 2010. Domain V peptides inhibit beta2-glycoprotein I-mediated mesenteric ischemia/reperfusion-induced tissue damage and inflammation. J. Immunol. 185, 6168-78.

Fruchterman T. M., Spain D. A., Wilson M. A., Harris P. D. and Garrison R. N., 1998. Complement inhbition prevents gut ischemia and endothelial cell dysfunction after hemorrhage/resuscitation. Surgery 124, 782-792.

Gries A., Nimpf J., Wurm H., Kostner G. M. and Kenner T., 1989. Characterization of isoelectric subspecies of asialo-beta 2-glycoprotein I. Biochem J 260, 531-4.

Gropp K., Weber N., Reuter M., Micklisch S., Kopka I., Hallstrom T. and Skerka C., 2011. betaglycoprotein I, the major target in antiphospholipid syndrome, is a special human complement regulator. Blood 118, 2774-83.

Hagihara Y., Hong D. P., Hoshino M., Enjyoji K., Kato H. and Goto Y., 2002. Aggregation of beta(2)glycoprotein I induced by sodium lauryl sulfate and lysophospholipids. Biochemistry 41, 1020-6.

Hammel M., Kriechbaum M., Gries A., Kostner G. M., Laggner P. and Prassl R., 2002. Solution structure of human and bovine beta(2)-glycoprotein I revealed by small-angle X-ray scattering. J Mol Biol 321, 85-97.

Hart M. L., Ceonzo K. A., Shaffer L. A., Takahashi K., Rother R. P., Reenstra W. R., Buras J. A. and Stahl G. L., 2005. Gastrointestinal ischemia-reperfusion injury is lectin complement pathway dependent without involving C1q. J. Immunol. 174, 6373-6380.

Hill J., Lindsay T. F., Ortiz F., Yeh C. G., Hechtman H. B. and Moore F. D., 1992. Soluble complement receptor type 1 ameliorates the local and remote organ injury after intestinal ischemiareperfusion in the rat. J. Immunol. 149, 1723-1728.

Kondo A., Miyamoto T., Yonekawa O., Giessing A. M., Osterlund E. C. and Jensen O. N., 2009. Glycopeptide profiling of beta-2-glycoprotein I by mass spectrometry reveals attenuated sialylation in patients with antiphospholipid syndrome. J Proteomics 73, 123-33.

Kulik L., Fleming S. D., Moratz C., Reuter J. W., Novikov A., Chen K., Andrews K. A., Markaryan A., Quigg R. J., Silverman G. J., Tsokos G. C. and Holers V. M., 2009. Pathogenic natural antibodies recognizing annexin IV are required to develop intestinal ischemia-reperfusion injury. J. Immunol. 182, 5363-73.

Laplante P., Amireault P., Subang R., Dieude M., Levine J. S. and Rauch J., 2011. Interaction of beta2Glycoprotein I with Lipopolysaccharide Leads to Toll-like Receptor 4 (TLR4)-dependent Activation of Macrophages. J Biol Chem 286, 42494-503.

Lee N. S., Brewer H. B., Jr. and Osborne J. C., Jr., 1983. beta 2-Glycoprotein I. Molecular properties of an unusual apolipoprotein, apolipoprotein $\mathrm{H}$. J Biol Chem 258, 4765-70.

Manfredi A. A., Rovere P., Heltai S., Galati G., Nebbia G., Tincani A., Balestrieri G. and Sabbadini M. G., 1998. Apoptotic cell clearance in systemic lupus erythematosus. II. Role of beta2-glycoprotein I. Arthritis Rheum 41, 215-23.

Martin F. and Kearney J. F., 2000. B-cell subsets and the mature preimmune repertoire. Marginal zone and B1 B cells as part of a "natural immune memory". Immunological Reviews 175, 70-79.

Meroni P. L., Raschi E., Testoni C., Tincani A., Balestrieri G., Molteni R., Khamashta M. A., Tremoli E. and Camera M., 2001. Statins prevent endothelial cell activation induced by antiphospholipid (antibeta2-glycoprotein I) antibodies: effect on the proadhesive and proinflammatory phenotype. Arthritis Rheum 44, 2870-8.

Moses T., Wagner L. and Fleming S. D., 2009. TLR4-mediated Cox-2 expression increases intestinal ischemia/reperfusion-induced damage. J. Leukoc. Biol. 86, 971-80. 
Nilsson M., Wasylik S., Morgelin M., Olin A. I., Meijers J. C., Derksen R. H., de Groot P. G. and Herwald H., 2008. The antibacterial activity of peptides derived from human beta-2 glycoprotein I is inhibited by protein $\mathrm{H}$ and $\mathrm{M} 1$ protein from Streptococcus pyogenes. Mol. Microbiol. 67, 482-92.

Pope M. R., Hoffman S. M., Tomlinson S. and Fleming S. D., 2010. Complement regulates TLR4-mediated inflammatory responses during intestinal ischemia reperfusion. Mol. Immunol. 48, 356-364.

Rehrig S., Fleming S. D., Anderson J., Guthridge J. M., Rakstang J., McQueen C. E., Holers V. M., Tsokos G. C. and Shea-Donohue T., 2001. Complement inhibitor, complement receptor 1-related gene/protein y-lg attenuates intestinal damage after the onset of mesenteric ischemia/reperfusion injury in mice. J. Immunol. 167, 5921-7.

Schousboe I., 1983. Characterization of subfractions of beta 2-glycoprotein I: evidence for sialic acid microheterogeneity. Int. J. Biochem. 15, 35-44.

Schultze H. E., 1961. [Glycoproteins of human plasma]. Bull. Schweiz. Akad. Med. Wiss. 17, 77-91.

Schwarzenbacher R., Zeth K., Diederichs K., Gries A., Kostner G. M., Laggner P. and PrassI R., 1999. Crystal structure of human beta2-glycoprotein I: implications for phospholipid binding and the antiphospholipid syndrome. EMBO J 18, 6228-39.

Sjogren R. W., Colleton C. and Shea-Donohue T. S., 1994. Intestinal myoelectric response in two different models of acute enteric inflammation. Am. J. Physiol. 267, G329-G337.

Sparkes B. L., Slone E. E., Roth M., Welti R. and Fleming S. D., 2010. Intestinal lipid alterations occur prior to antibody-induced prostaglandin E2 production in a mouse model of ischemia/reperfusion. Biochim Biophys Acta 1801, 517-25.

Srivastava A. S., Feng Z., Mishra R., Malhotra R., Kim H. S. and Carrier E., 2007. Embryonic stem cells ameliorate piroxicam-induced colitis in IL10-/- KO mice. Biochem. Biophys. Res. Commun. 361, 953-9.

Stefas I., Dubois G., Tigrett S., Lucarz E. and Veas F., 2011. Apolipoprotein H, an acute phase protein, a performing tool for ultra-sensitive detection and isolation of microorganisms from different origins. In Veas F. (Ed.), InTechWeb.

Tolomeo T., Rico De Souza A., Roter E., Dieude M., Amireault P., Subang R., Levine J. S. and Rauch J., 2009. T cells demonstrate a Th1-biased response to native beta2-glycoprotein I in a murine model of anti-phospholipid antibody induction. Autoimmunity 42, 292-5.

Weiser M. R., Williams J. P., Moore F. D., Kobzik L., Ma M., Hechtman H. B. and Carroll M. C., 1996. Reperfusion injury of ischemic skeletal muscle is mediated by natural antibody and complement. J. Exp. Med. 183, 2343-2348.

Williams J. P., Pechet T. T. V., Weiser M. R., Reid R., Kobzik L., Moore F. D., Carroll M. C. and Hechtman H. B., 1999. Intestinal reperfusion injury is mediated by IgM and complement. J. Appl. Physiol. 86, 938-942.

Wurm H., 1984. beta 2-Glycoprotein-I (apolipoprotein H) interactions with phospholipid vesicles. Int. J. Biochem. 16, 511-5.

Zhang M., Austen W. G., Chiu I., Alicot E. M., Humg R., Ma M., Verna N., Xu M., Hechtman H. B., Moore F. D. and Carroll M. C., 2004. Identification of a specific self-reactive IgM antibody that initiates intestinal ischemia/reperfusion injury. Proc. Natl. Acad. Sci. U. S. A. 101, 3886-3891. 
Figure 1 Sham
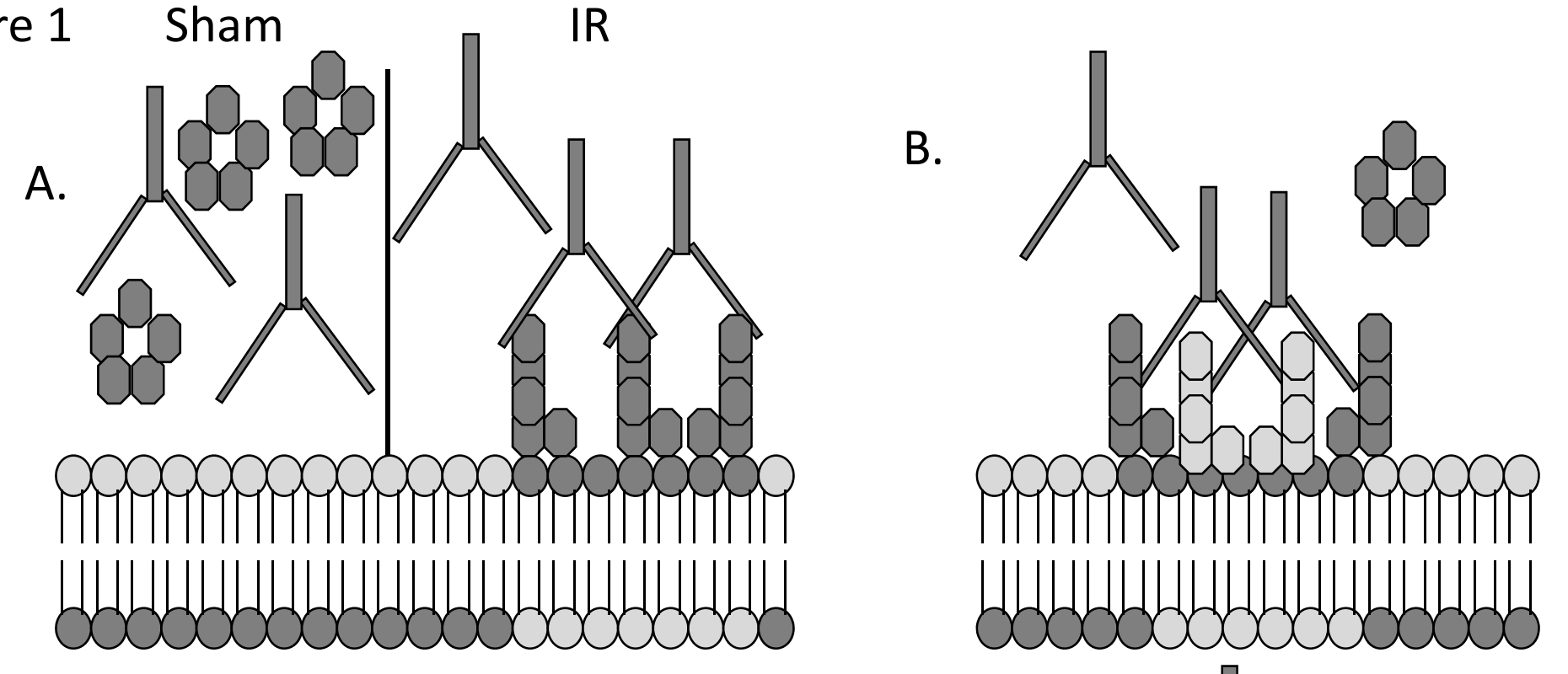
1 Closed conformation $\beta 2-G P I$

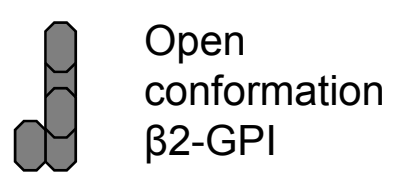

c.
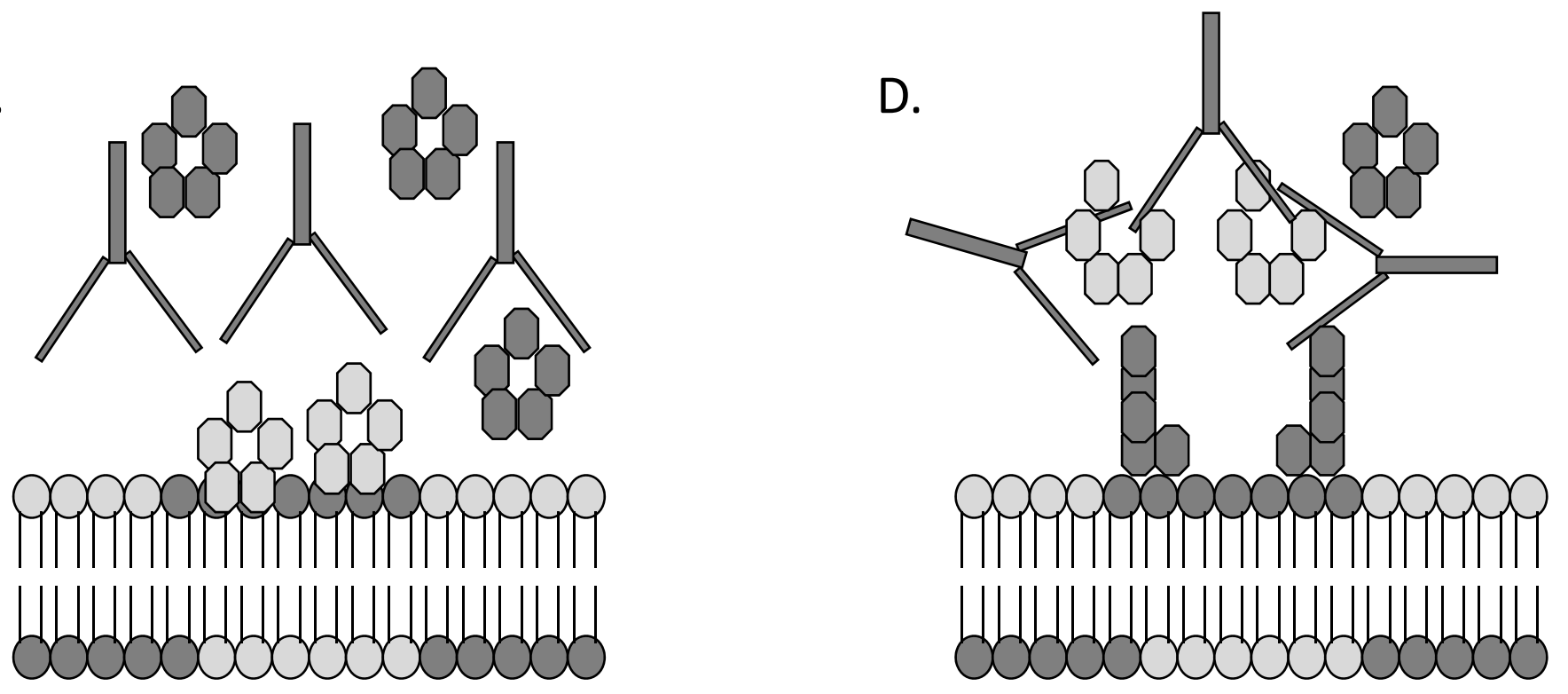
antibody 
Figure 2

A.

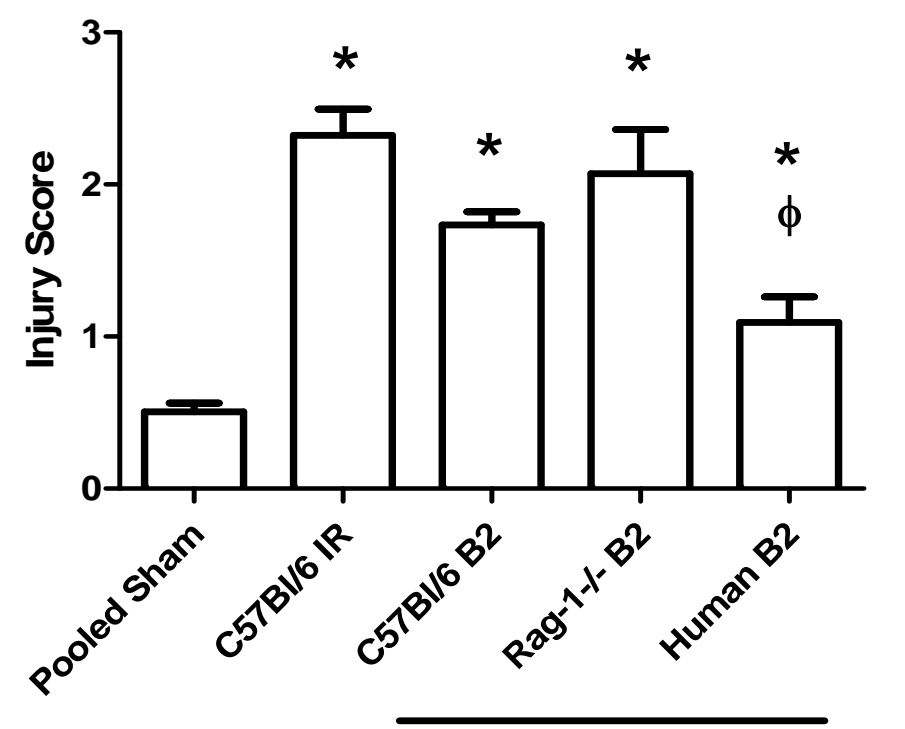

B.

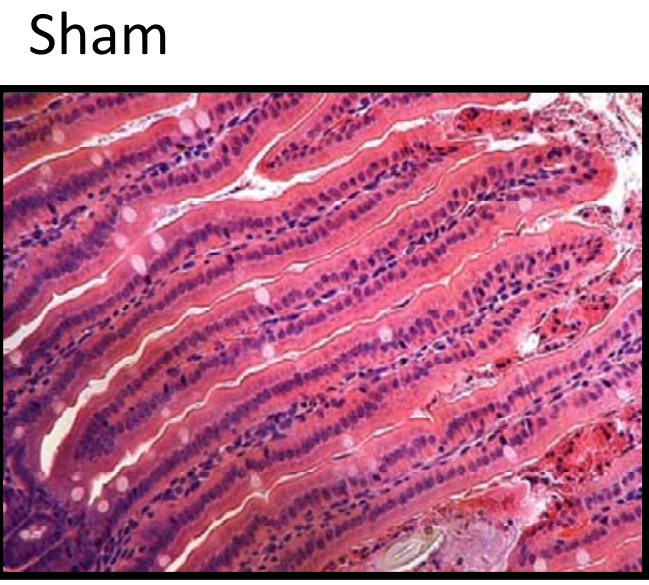

C57BI/6 IR+
D.

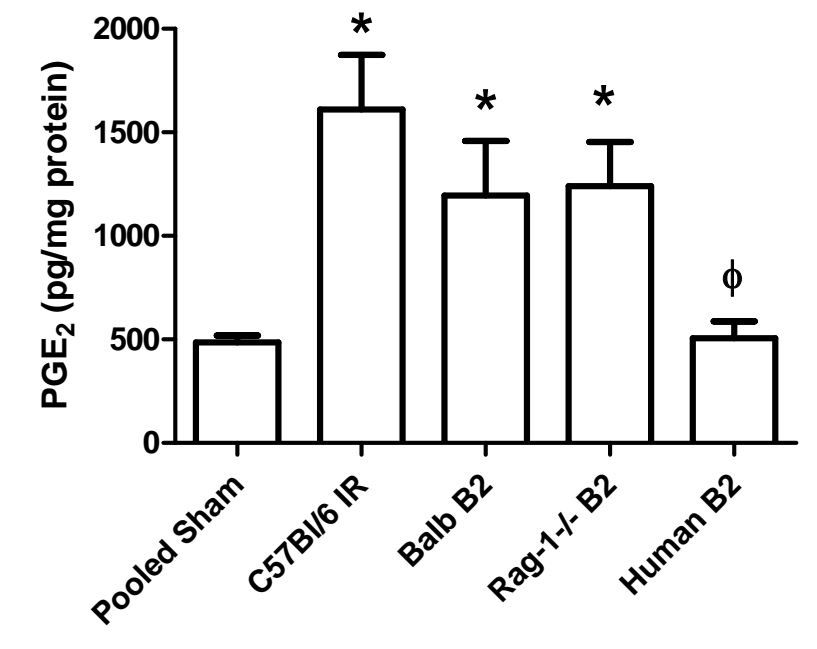

E. IR + Rag-1-/- B2

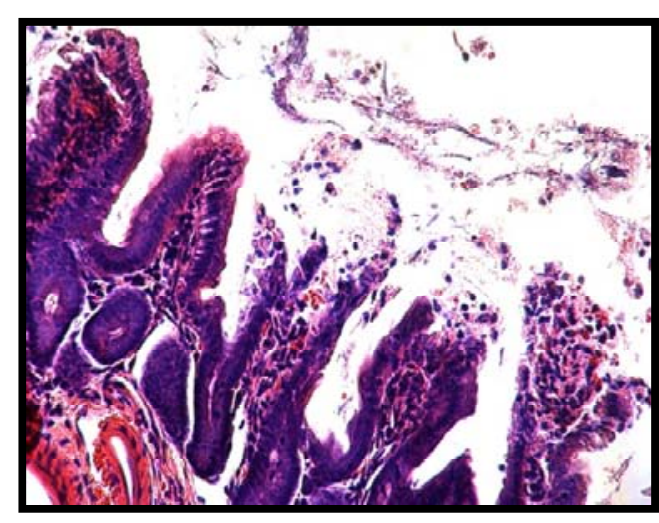

C.

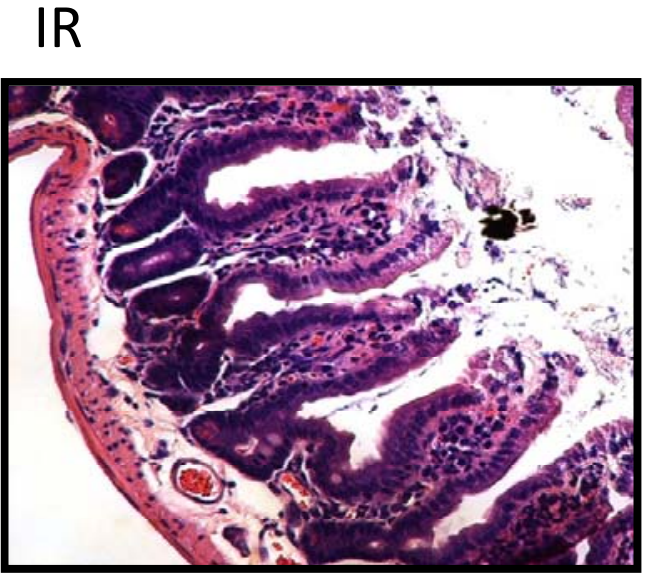

F. IR + Human B2

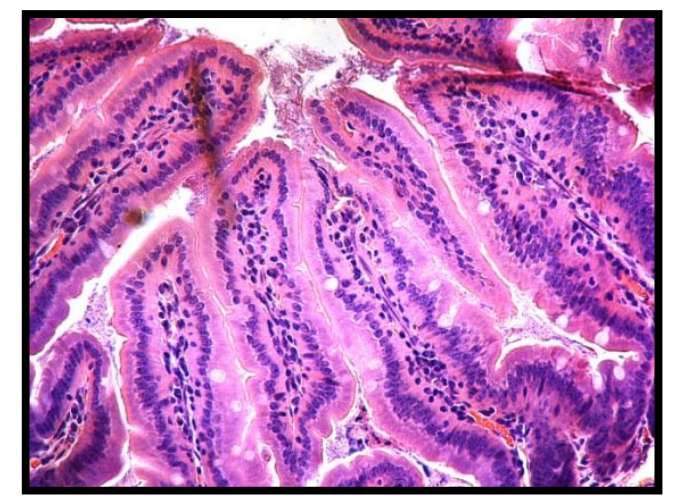

C57BI/6 IR+ 
Figure 3

A.

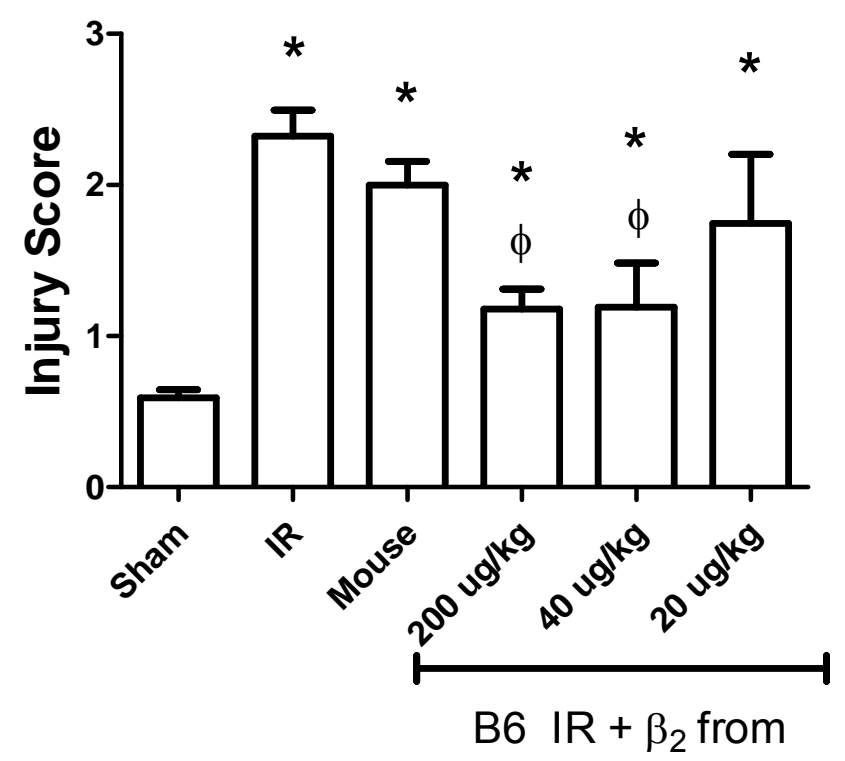

B.

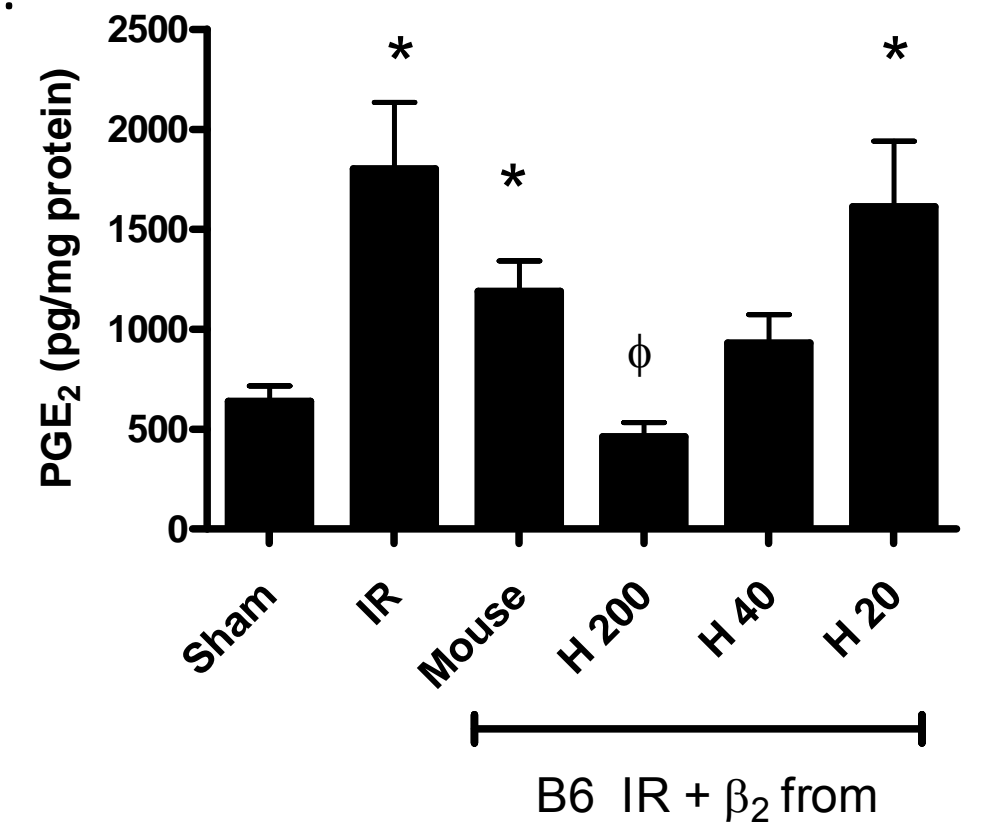


Figure 4

A. B6 Sham

B. B6 IR
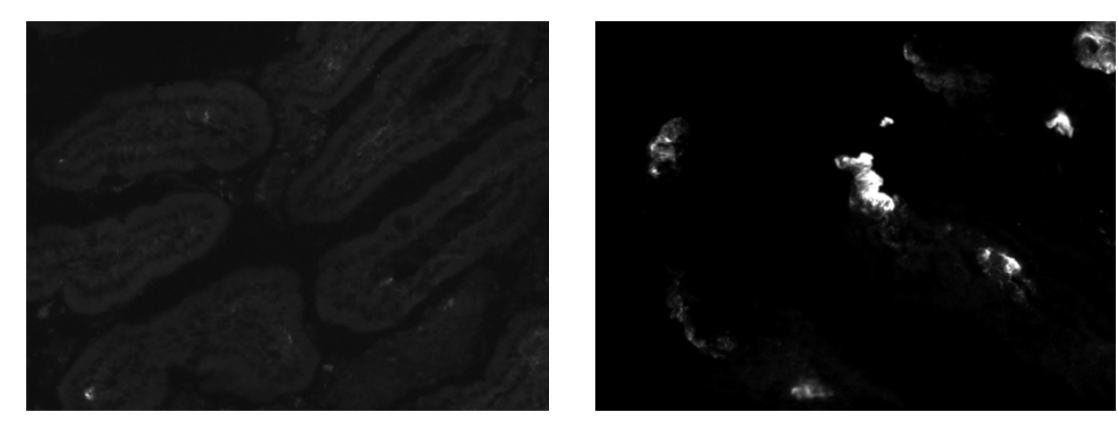

C. B6 IR +HumanB2

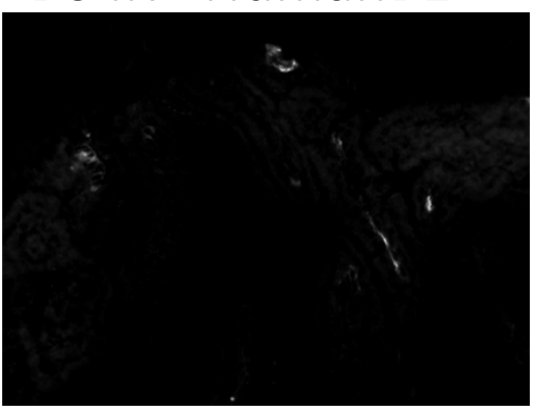

D. B6 IR +Mouse B2

E. Isotype
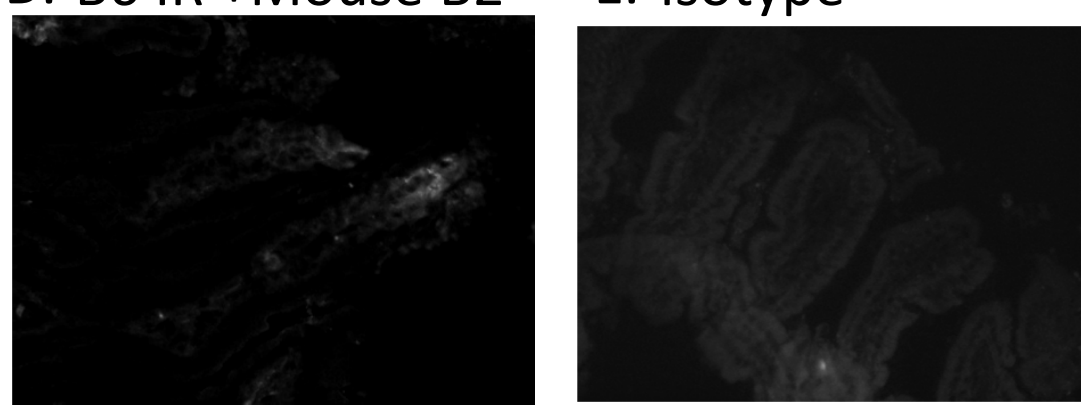
Figure 5

A.

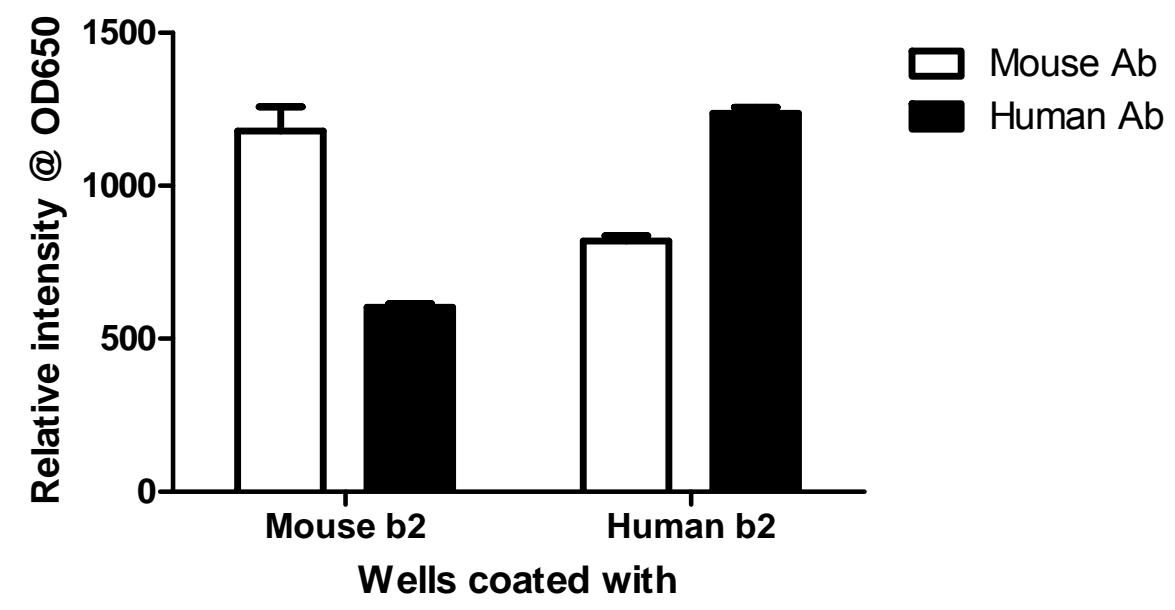

B.

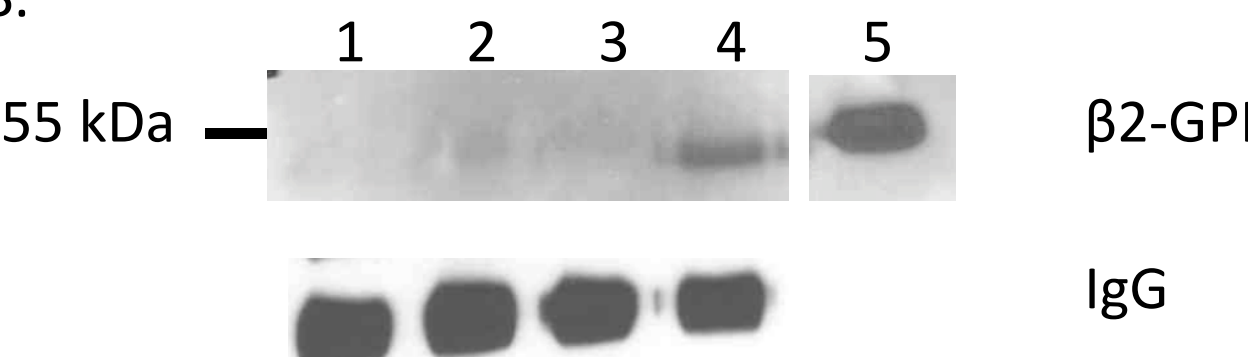


Figure 6
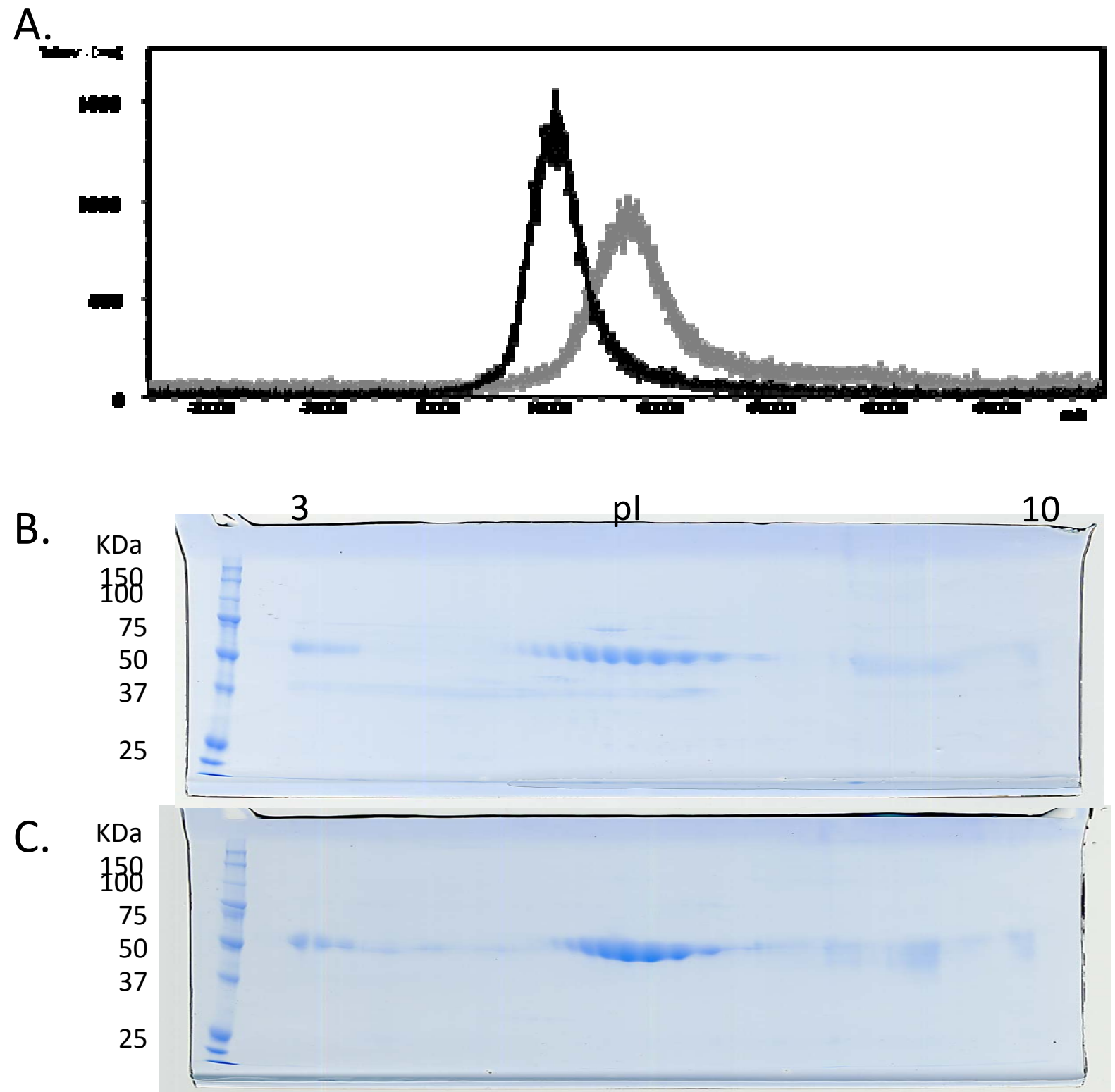
Figure 7

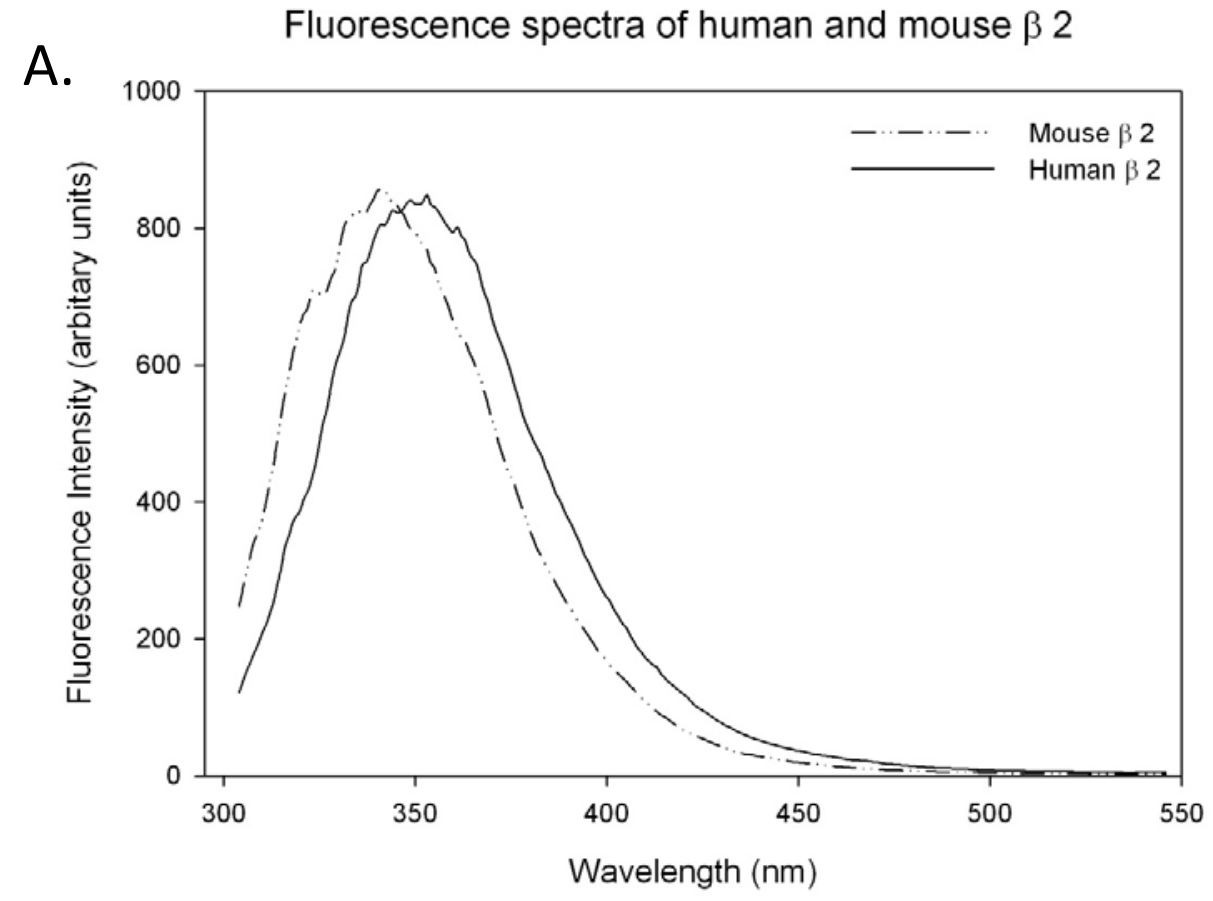

B.

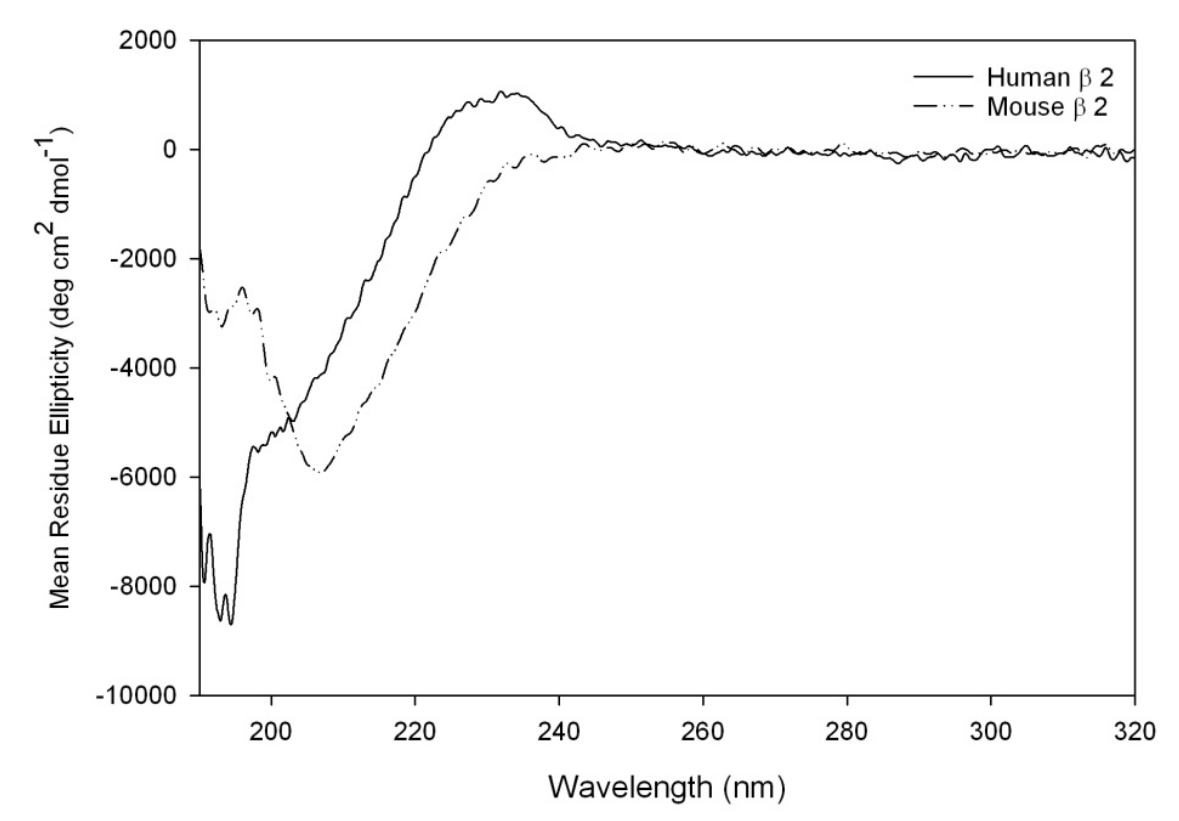




\section{SDS-PAGE}

$10 \%$ Sep. gel

Reduced

condition
12

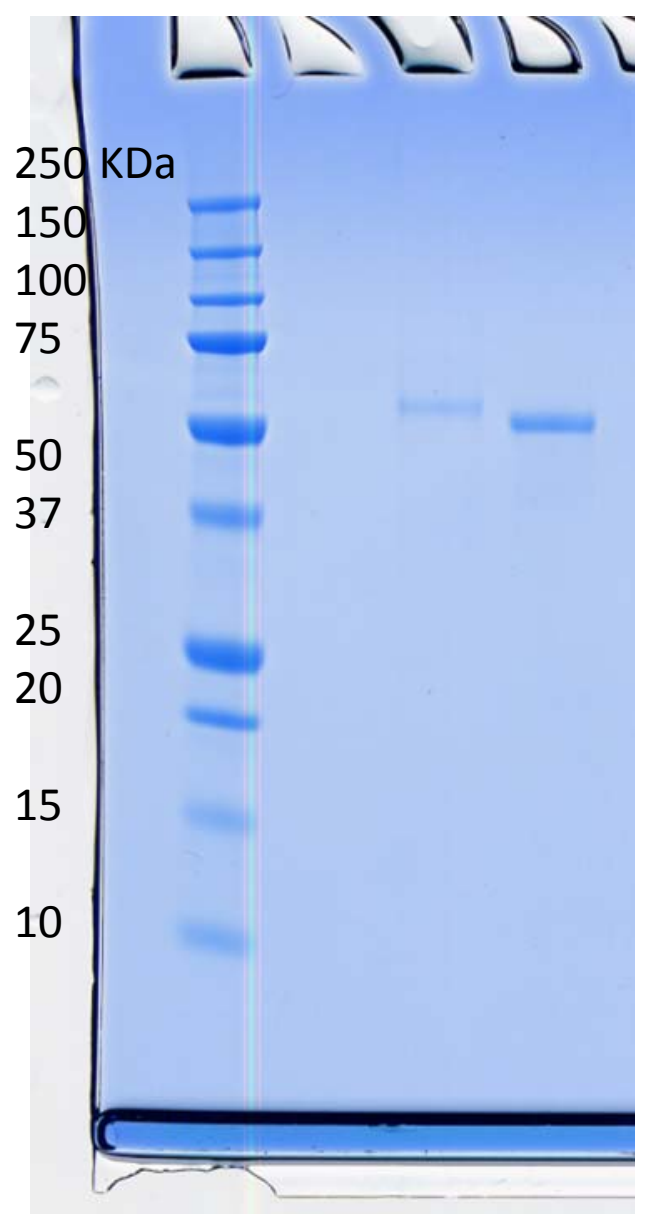

$\begin{array}{llll}3 & 4 & 5 & 6\end{array}$

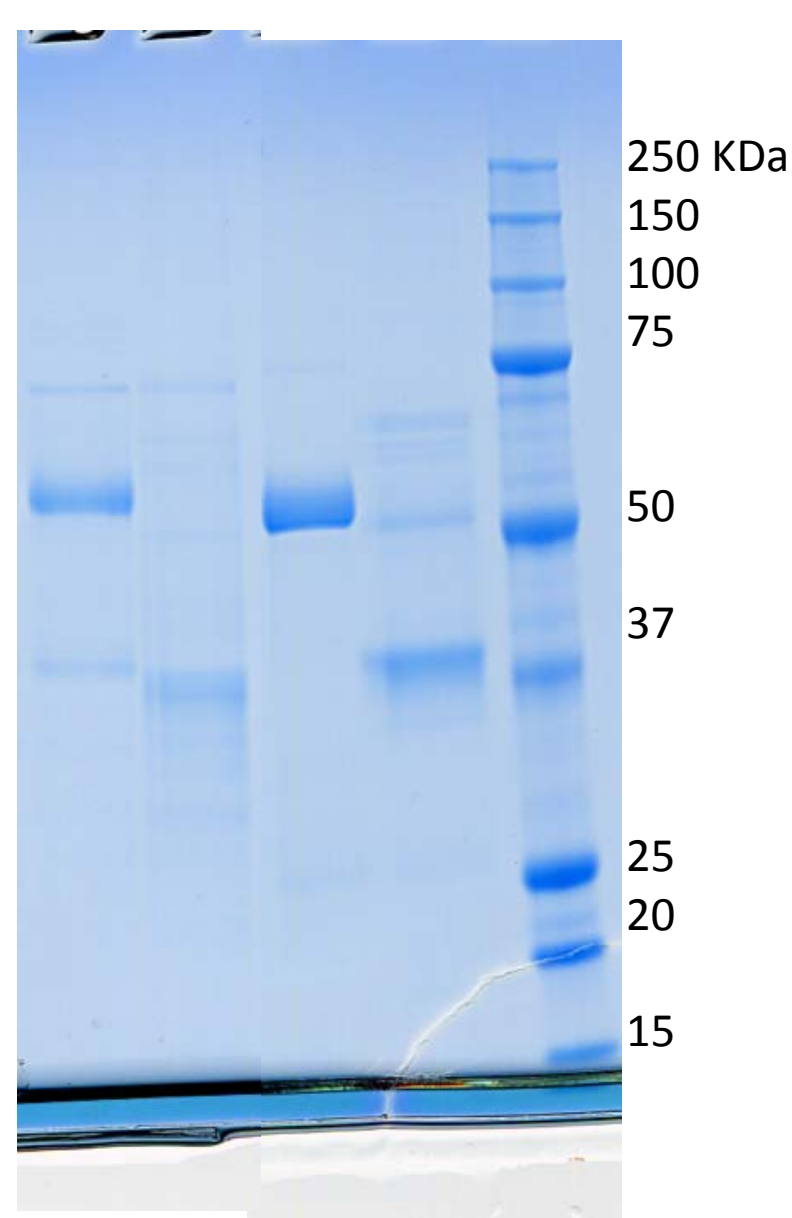

lane 1: Mouse $\beta 2-G P I$ lane 2: Human $\beta 2$-GPI lane 3: Mouse $\beta 2-\mathrm{GPI}$ lane 4: Mouse $\beta 2-G P I+P N G a s e ~ F$ lane 5: Human $\beta 2-G P I$ lane 6: Human $\beta 2-$ GPI + PNGase F 


\section{ESI-MS coverage}

$\begin{array}{ccc} & \text { Leader sequence } & \text { Sushi } 1 \\ \text { Human } & \text { MISPVLILFSSFLCHVAIAGRTCPKPDDLPFSTVVPLKTFYEPGEEITYSCKPGYVSRGG } & 60 \\ \text { Mouse } & \text { M+SPVL LFS+FLCHVAIAGR } & \text { CPKPDDLPF+TVVPLKT Y+PGE+I YSCKPGYVSRGG } \\ & \text { MVSPVLALFSAFLCHVAIAGRICPKPDDLPFATVVPLKTSYDPGEQIVYSCKPGYVSRGG } & \text { Sushi 2 } \\ & \text { Sushi } 1 & \end{array}$

MRKFICPLTGLWPINTLKCTPRVCPFAGILENGAVRYTTFEYPNTISFSCNTGFYLNGAD 120 $M R+\bar{F}$ CPLTG+WPINTL+C PRVCPFAGILENG VRYT+FEYP ISF+CN GF+LNG MRRFTCPLTGMWPINTLRCVPRVCPFAGILENGIVRYTSFEYPKNISFACNPGFFLNGTS 120

Sushi 2

Sushi 3

SAKCTEEGKWSPELPVCAPIICPPPSIPTFATLRVYKPSAGNNSLYRDTAVFECLPQHAM 180 S+KCTEEGKWSP++P CA I CPPP +P FA L+ Y+PSAGNNSLY+DT VF+CLP AM SSKCTEEGKWSPDIPACARITCPPPPVPKFALLKDYRPSAGNNSLYQDTVVFKCLPHFAM 180

Sushi 3

Sushi 4

FGNDTITCTTHGNWTKLPECREVKCPFPSRPDNGFVNYPAKPTLYYKDKATFGCHDGYSL 240 GNDT+ CT GNWT+LPEC EVKCPFP RP+NG+VNYPAKP L YKDKATFGCH+ Y L IGNDTVMCTEQGNWTRLPECLEVKCPFPPRPENGYVNYPAKPVLLYKDKATFGCHETYKL 240

Sushi 4

DGPEEIECTKLGNWSAMPSCKASCKVPVKKATVVYQGERVKIQEKFKNGMLHGDKVSFFC 300 DGPEE ECTK G WS +P+C+ SCK+PVKKATV+YQG RVKIQE+FKNGM+HGDK+ F+C DGPEEAECTKTGTWSFLPTCRESCKLPVKKATVLYQGMRVKIQEQFKNGMMHGDKIHFYC 300

KNKEKKCSYTEDAQCIDGTIEVPKCFKEHSSLAFWKTDASDVKPC 345 KNKEKKCSYT +A C DGTIE+P CFKEHSSLAFWKTDAS++ PC

KNKEKKCSYTVEAHCRDGTIEIPSCFKEHSSLAFWKTDASELTPC 345 $\mathrm{Red}$ N-glycosylation site

Underline: detected at ESI-MS/MS 
